\title{
CONFIGURACIÓN ECONÓMICA DE BAJA CALIFORNIA
}

\author{
Por \\ Jorge García Montaño*
}

\begin{abstract}
RESUMEN
Este estudio tiene como finalidad realizar una comparación entre la economía de Baja California con la del resto del país, tomando en cuenta los cambios que han sufrido las actividades económicas del estado.

También se plantea que Baja California, por su situación geográfica, desarrolla un modelo de crecimiento diferente al resto del país, haciendo hincapié en los factores que se encuentran relacionados con la economía internacional.
\end{abstract}

\begin{abstract}
This paper intends to establish a comparison between the economy of Baja California and that of Mexico as a whole, taking in consideration the changes occurred within the economic activities of the state.

It is also suggested that Baja California due to its geographic location develops a model of growth different than the rest of the country, emphasizing these factors in relation with the international economy.
\end{abstract}

\section{INTRODUCCIÓN}

El objetivo de este ensayo es presentar un panorama de la estructura económica de Baja California con el fin de exponer un marco general del comportamiento económico para los años de 1970 a 1990 y sus perspectivas para los años futuros.

El presente estudio tiene especial interés en los siguientes temas: 1) realizar una comparación entre la economía de Baja California (B.C.) con la de México, definiendo sus modelos y sus ciclos económicos; 2) analizar los cambios que han sufrido las principales actividades económicas del estado, ponderando algunos problemas que son parte de la crisis económica de México y que influyen de manera especial en la entidad: inflación, devaluaciones y sector

- Secretario ejecutivo del Centro de Estudios para el Desarrollo de la Administración Municipal, A.C. (CRDAM). 
externo; por último, 3) estudiar la importancia de la frontera norte de México y de la política económica para la conformación de la estructura económica de Baja California.

La hipótesis que planteamos es que Baja California, por su historia y su situación geoeconómica, desarrolla un modelo y un estilo de crecimiento "diferente" al resto del país; dichas diferencias se deben principalmente a su ubicación en la frontera norte de México. Es decir, que ante todo influyen factores que se encuentran relacionados con la economía internacional; en especial, con los Estados Unidos y, en concreto, con el estado de California.

Esto implica dos aclaraciones: a) en B.C. existe un modelo y un estilo de crecimiento económico que es relativamente diferente al de México, mas no independiente del contexto nacional y en especial de las políticas económicas del estado mexicano; b) el estilo de comportamiento "específico" de la economía bajacalifomiana permite responder de un modo difcrente a los problemas que implican los desajustes económicos que existen desde 1976 a nivel nacional; especialmente a los procesos devaluatorios y a los cambios del sector externo.

Antes de iniciar el desarrollo del estudio es conveniente exponer algunos criterios metodológicos: hacemos múltiples referencias comparativas entre Baja California y México; esto se hace con el objetivo de demostrar igualdades y diferencias existentes entre estas dos unidades. Estamos conscientes de los límites y riesgos que dicha comparación implica, pues se sustentan en medias o en per cápita, pero no encontramos otra opción para hacer resaltar las "especificidades" de la sociedad bajacaliforniana.

Entendemos por modelo económico a la estructura económica y al patrón de comportamiento de una formación socioeconómica que hace referencia a las actividades más permanentes en el tiempo de una sociedad. En cambio, cuando hablamos de estilos de comportamiento hacemos referencia a la manera en que el modelo se comporta frente a eventos coyunturales de gran magnitud socioeconómica, por ejemplo: las políticas económicas, las devaluaciones y la inflación que a largo plazo pueden impactar a su vez la estructura.

En todo el trabajo se hace referencia al concepto de crisis; éste se define como una situación donde el producto interno bruto tiene una tasa de crecimiento media anual (TCMA) negativa; en aquellos años donde dicha tasa es constante hablaremos de estancamiento; cuando la tasa disminuye de un año a otro pero no llega a ser negativa hablaremos de recesión. Cuando la tasa es positiva nos encontramos en crecimiento y si la TCMA es considerablemente alta, hablamos de auge económico. ${ }^{1}$ Estos estados del ciclo económico son las fases componentes del comportamiento de la estructura. 


\section{MODELO Y CICLOS ECONÓMICOS}

Baja California es una entidad federativa de México ubicada en la frontera norte del país, de relativa historia. ${ }^{2}$ Consta de cuatro municipios, tres de los cuales son ciudades fronterizas: Mexicali, Tijuana y Tecate y un puerto, Ensenada.

La sociedad bajacaliforniana es relativamente nueva pues se constituye a finales del pasado siglo, y como estado de la federación en 1953. Es apenas en la década de los veinte cuando se consolidan dos frentes económicos de importancia: "uno directamente vinculado con la agricultura del valle de Mexicali y presidido por el capital norteamericano, y otro desprendido del mercado prohibicionista, que abarcó a todo el estado y en el que coexistieron los capitales nacionales y extranjeros." (Contreras, 1988:45). El valle de Mexicali ${ }^{3}$ y las actividades turísticas y de servicios de Tijuana se desarrollaron en base a la ley que en 1929 prohibió en los Estados Unidos los juegos de azar y el consumo de alcohol.

Fueron estos dos tipos de actividad las que generaron el inicio de un mercado interno para las inversiones y el empleo de la entidad. Posteriormente, en los años treinta, con la reforma agraria del gobierno cardenista en contra de las compañias deslindadoras, se inicia el surgimiento de un grupo social de pequeños y medianos empresarios, que respondieron no sólo a la demanda externa - que en aquel entonces venía de la próspera California - sino también de la demanda interna, activăndose de esta manera el mercado local.

Los primeros núcleos de población en la entidad nacieron al amparo de las compañías deslindadoras en el valle de Mexicali, de un fracasado auge de la minería en Ensenada y de las actividades turisticas y de servicios de Tijuana. La historia económica de la entidad se consolida con la implementación del régimen aduanal de excepción llamada "Perímetros y zona libre" implementado en 1933, inicialmente sólo para Tijuana y Ensenada, y extendida en 1937 a todo el estado (Negrete, 1986:37).

\footnotetext{
1 Crecimiento económico, entonces, se define como el aumento en el valor agregado del promedio general de los diferentes sectores económicos. No se habla de "desarrollo económico" pues éste concepto hace referencia no sólo a un crecimiento del valor agregado sino también a un aumento en los niveles de vida de la población, situación que nó analizamos profundamente.

2 En el texto Sintesis geográfica del estado de Baja California (INEGI-SPp, 1982) se pueden encontrar las definiciones geográficas exactas del estado.

${ }^{3}$ La base del orecimiento del valle de Méxicali se debió a la llamada "política de colonización" que impulsaron varias empresas extranjeras en la entidad: las "compañías deslindadoras". La principal de ellas fue la Colorado River Land Company (véase Herrera, 1976).
} 


\section{Sin duda alguna,}

el impulso más significativo con respecto al modelo de industrialización bajacaliforniano fue posible una vez que la transformación de las condiciones de producción agrícola, junto con la evolución favorable de los mercados de exportación - "gracias a la II guerra mundial y a la guerra de Corea" - dio lugar a un ritmo de acumulación que rebas 6 su marco agrícola originario y se canalizó hacia los sectores industrial y comercial de manera ampliada (Sández, 1987:11).

Una parte importante del crecimiento económico de la entidad provino de la demanda generada por la economía de California, y concretamente de la región sureña; esto "le confiere características que muestran más acabadamente las distintas etapas por las que ha pasado la frontera en los últimos setenta años" (Zazueta, 1978:4).

Entre las características fronterizas destacan: 1) el rápido crecimiento demográfico y económico; 2) desvinculación relativa con el resto del país en términos económicos; 3) foco de atracción migratoria; y 4) fuerte interrelación con los Estados Unidos. ${ }^{4}$

La concentración de la población bajacaliforniana responde en mucho a la ubicación de las zonas urbanas en la frontera; es ahí donde se generan las principales actividades económicas, y por ende donde se encuentran los mercados de trabajo, de servicios y bienes; ya sea que los municipios posean recursos naturales, como Mexicali, o una serie de actividades económicas internacionales como Tijuana.

Para tener una mejor idea del crecimiento de la entidad, en el cuadro 1 presentamos el comportamiento de la población de México y Baja California. El decenio donde más crece la población de la entidad fue en la década de los cuarenta: $11.00 \%$, mientras que el país tuvo una tasa de crecimiento de $2.75 \%$. Para los siguientes años se inicia una lenta caída de la tasa de crecimiento poblacional para Baja California: durante la década de los cincuenta y sesenta de 8.65 y $5.28 \%$, respectivamente.

\footnotetext{
4 "Además, Baja Califomia responde a prácticamente todas las demandas provenientes de los EUA1) [...] el país abre parte de su territorio a ciudadanos norteamericanos quienes pasan a ocupar posiciones de dominio sobre las tierras de mejor calidad en todo el territorio [...] 2) Cercana en el tiempo a la penetración y dominio de sus téerras, Baja California, como buena parte del resto de la frontera, responde a las demandas de servicios que le hacen del otrolado como resultado de la prohibición [...] 3) La situación intermacional de finales de la década de los años treinta, que desembocará en la segunda guerra mundial, será otro factor que impulse decididamente el desarrollo de la región y de Baja Califomia en particular" (Zazueta, 1978).
} 
Según los datos disponibles - con los ajustes pertinentes a los datos censales-, la tasa de crecimiento en la entidad se regulariza alrededor de un $3 \%$ en 1990, y posiblemente tienda para el año 2000 a una tasa anual de crecimiento del $2 \%$, acercándose cada vez más a la de México.

Es interesante destacar también que el porcentaje de participación del total de la población bajacaliforniana en la de México va de un intervalo del $0.31 \%$ en 1930 a $2.16 \%$ en 1990 ; también con una tendencia a estabilizar su participación en la población total de México alrededor del $2.50 \%$. En la figura 1 se observan las TCMA de las poblaciones y el porcentaje de participación de la población de la entidad respecto a la de México.

\section{CUADRO 1. Población total de México y de Baja California 1930-1990.}

\begin{tabular}{|c|c|c|c|c|c|}
\hline \multirow[b]{2}{*}{ Años } & \multicolumn{2}{|c|}{ Población total: } & \multicolumn{2}{|c|}{ TCMA: } & \multirow{2}{*}{$\begin{array}{l}\% \text { de B.C. } \\
\text { en México }\end{array}$} \\
\hline & México & B.C. & México & B.C. & \\
\hline 1930 & 15552722 & 48327 & & & 0.31 \\
\hline 1940 & 19653552 & 79907 & 2.37 & 5.16 & 0.41 \\
\hline 1950 & 25791017 & 226965 & 2.75 & 11.00 & 0.88 \\
\hline 1960 & 34923129 & 520165 & 3.08 & 8.65 & 1.49 \\
\hline 1970 & 48225238 & 870421 & 3.28 & 5.28 & 1.80 \\
\hline 1975 & 58940179 & 1111169 & 4.09 & 5.01 & 1.89 \\
\hline 1980 & 69655120 & 1351916 & 3.40 & 4.00 & 1.94 \\
\hline 1985 & 77904652 & 1607609 & 2.26 & 3.53 & 2,06 \\
\hline 1990 & 86154184 & 1863301 & 2.03 & 3.00 & 2.16 \\
\hline 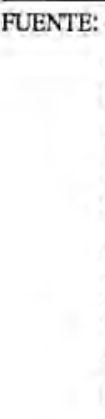 & $\begin{array}{l}\text { nsos generales } \\
\text { 1990: "Proyecc } \\
\text { derativas", (hip } \\
\text { sultados prelim } \\
\text { EGl, estimó } 81 \\
\text { lifornia de } 193 \\
1990 \text { son ajuste } \\
\text { blación total d } \\
\text { tudios y proye } \\
\text { sultados prelim } \\
\text { ja California. }\end{array}$ & $\begin{array}{l}\text { población d } \\
\text { nes de la pob } \\
\text { esis de fecund } \\
\text { ares. XI cens } \\
0,922 \text { habita } \\
\text { 1960: Censo } \\
\text { estimacione } \\
\text { Mexicali, Ba } \\
\text { s, (XII Ayun } \\
\text { ares del INEGI } \\
\text { s poblaciones }\end{array}$ & $\begin{array}{l}30 \text { a } 1960 . \\
\text { n de Méxi } \\
\text { altemativa } \\
\text { neral de } p \\
\text { para marzo } \\
\text { nerales de } \\
\text { "Análisis } \\
\text { alifomia: } 1 \\
\text { tento de M } \\
\text { naron 1' } 65 \\
980 \text { y } 199\end{array}$ & $\begin{array}{l}\text { Para Mé } \\
\text { co y de } \\
\text { ), CONEI } \\
\text { oblaciór } \\
\text { de } 199 \\
\text { població } \\
\text { le la val } \\
990^{\circ "}, C \\
\text { exicali, } \\
7,927 \text { ha }\end{array}$ & $\begin{array}{l}\text { xico de } 1980 \\
\text { las entidades } \\
\text { O-INEGi. Los } \\
\text { y vivienda. } \\
\text { 0. Para Baja } \\
\text { n. Para } 1970 \\
\text { idación de la } \\
\text { uadernos de } \\
\text { 1990b). Los } \\
\text { bitantes para } \\
\text { nitad de año. }\end{array}$ \\
\hline
\end{tabular}


Otro dato importante es el comportamiento de la población económicamente activa (PEA) (ver cuadro 2). En 1970 el porcentaje de la PEA de México respecto a su población era mayor que la de Baja California pero desde 1975 esta relación se invierte, hasta que en 1990 las diferencias son del 5\% a favor de la entidad; lo que hace que las presiones del mercado de trabajo sean mayores en la entidad que el promedio nacional (ver figura 2).

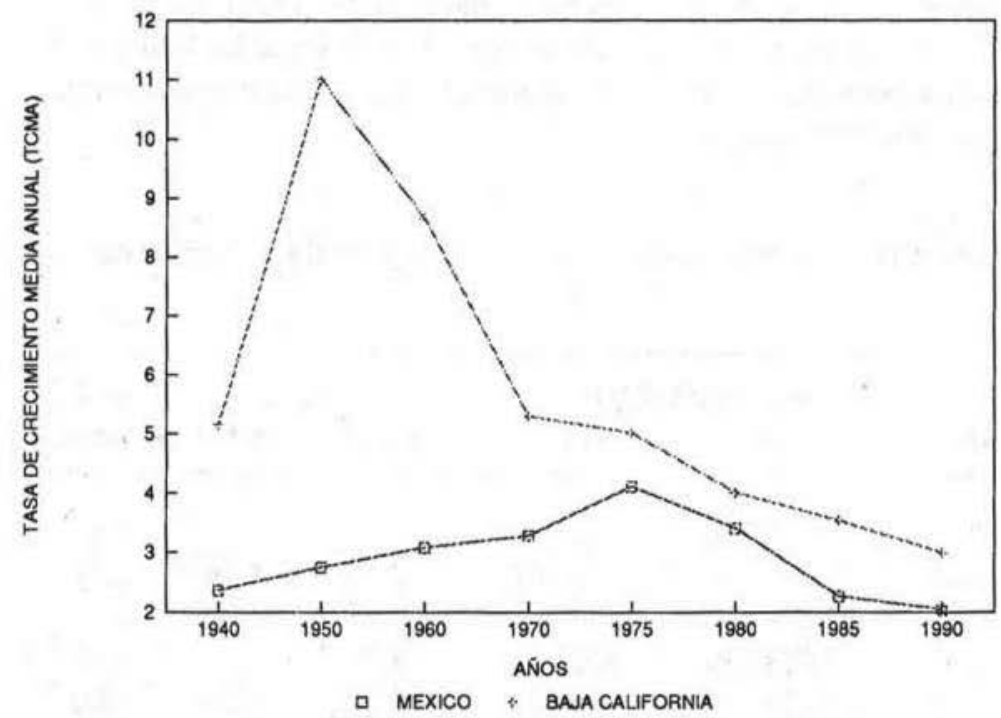

FIGURA 1. TCMA de la población total 1940-1990; México y Baja California.

FUENTE:Misma del cuadro 1.

Es la estructura demográfica de la entidad la que explica aquellas diferencias: Baja California es el primer estado donde la fecundidad desciende de una forma considerable; la tasa de mortalidad es una de las más bajas a nivel nacional y la inmigración está concentrada en los grupos de edad productiva.

Son los grupos de edad de 14 a 64 años los que a partir de 1990 presionan y empiezan a ser el grueso de la población. Tanto así que estimamos que para el inicio del próximo siglo el porcentaje de la PEA en relación a la población total en la entidad llegará al $40 \%$, mientras que a nivel nacional será alrededor del $32 \%$. 
CUADRO 2. Población económicamente activa (PEA) total de México y de Baja California 1970-1990.

\begin{tabular}{|c|c|c|c|c|c|c|c|}
\hline \multirow[b]{2}{*}{ Años } & \multicolumn{2}{|c|}{ PEA } & \multicolumn{2}{|c|}{$\%$ PEA en PT } & \multicolumn{2}{|c|}{ TCMA } & \multirow{2}{*}{$\begin{array}{l}\% \text { de B.C } \\
\text { en México }\end{array}$} \\
\hline & México & B.C. & México & B.C. & México & B.C. & \\
\hline 1970 & 12955000 & 221779 & 26.86 & 25.48 & & & 1.71 \\
\hline 1975 & 17510500 & 341207 & 29.71 & 30.71 & 6.21 & 9.00 & 1.95 \\
\hline 1980 & 22066000 & 460634 & 31.68 & 34.07 & 4.73 & 6.19 & 2.09 \\
\hline 1985 & 24033000 & 560042 & 30.85 & 34.84 & 1.72 & 3.99 & 2.33 \\
\hline 1990 & 26000000 & 659450 & 30.18 & 35.39 & 1.59 & 3.32 & 2.54 \\
\hline
\end{tabular}

FUENTE: Las mismas del cuadro 1. Para 1985 y 1990: Nacional financiera, S.N.C, Gerencia de información técnica y publicaciones. "Estimaciones y proyecciones de población, 1950-2000". SSP, INEGI y CELADE.

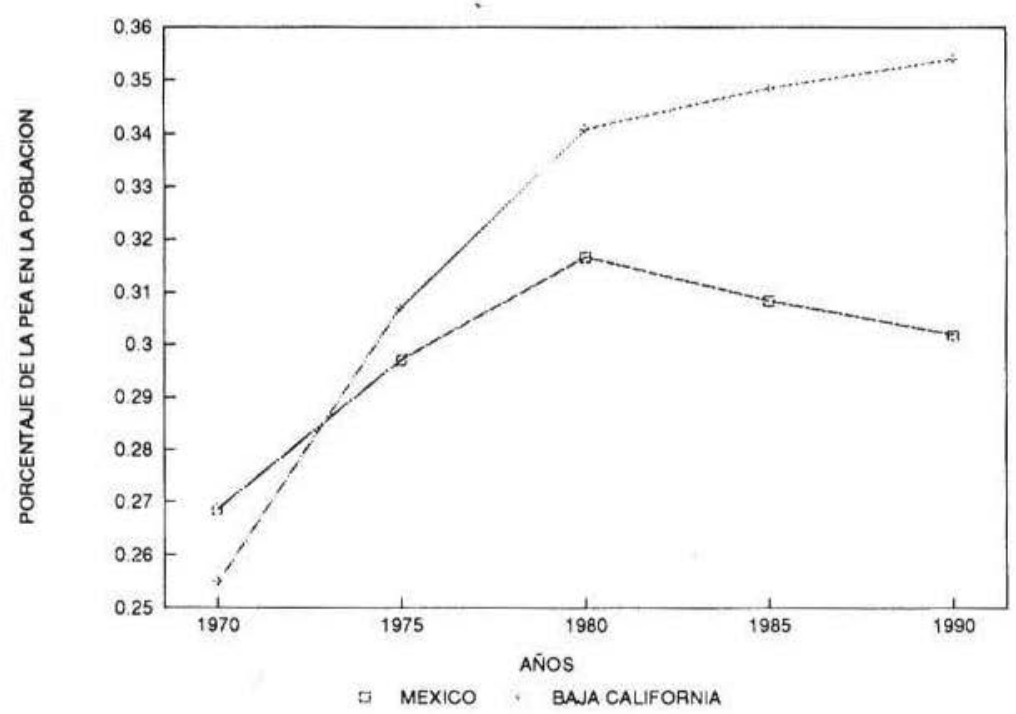

FIGURA 2. Porcentaje de la PEA en la población. 1940-1990; México y Baja California.

FUENTE:Misma de cuadro 2. 
De lado del fuerte crecimiento de la población existe el desarrollo de la economía que ha privilegiado a la industria y a los servicios, concentrándose en las zonas urbanas del país.

Históricamente, México comenzó su proceso de sustitución de importaciones, como la mayoría de los países latinoamericanos, por la vía más fácil: la producción de bienes de consumo no durables; no sólo por cuestiones técnicas sino porque el mercado interno lo permitía.

De 1956 a 1970, el país transitó por el llamado "desarrollo estabilizador": durante esos años la economía creció en $6.74 \%$ promedio anual, ${ }^{5}$ con una fuerte estabilidad en los precios ( $4,22 \%$ promedio anual). A pesar de ello el desequilibrio exterior de la economía nacional fue permanente. En este contexto no hay que olvidar que el país cuenta con diferentes formas de producción: la capitalista y la estatal, la mercantil simple y la forma de producción doméstica (Boltvinik, 1986; 206).

Las formas de producción capitalista y estatal fueron las que más crecieron durante aquellos años, determinando la tasa de crecimiento de Ia economía. Terminada la década de los setenta, se inicia un moderado crecimiento y el regreso a la inflación. Durante 1971 a 1976 la tasa media de crecimiento de la economía fue de alrededor del $6 \%$ con una inflación del $15 \%$ promedio anual, tal como se observa en los cuadros 3 y 4 , es decir, fueron años de franco crecimiento. En los siguientes párrafos desarrollaremos algunas de las ideas aquí expuestas de manera general.

En el cuadro 3 se presenta la dinámica del PIB para México y Baja California. En éste se destaca que en el crecimiento de México existen claramente cuatro fases del periodo ${ }^{6}$ de 1970 a 1990; primera fase: 1970-1976, de crecimiento; segunda: 1977 a 1981, de auge; tercera: de crisis de 1982 a 1986 y de estancamiento o recesión de 1987 a 1990. actualmente, entra en una fase de crecimiento relativo.

Las fases para Baja California parecen no diferenciarse mucho del ciclo nacional, aunque existen ciertas diferencias a destacar: a) en la primera fase, el crecimiento es más sostenido; b) durante la fase de auge, la TCMA de la entidad es más sostenida y de mayor altura; c) la crisis impacta menos

5 El concepto más usado para medir el crecimiento económico y sus ciclos en los países es el producto interno bruto (PIB) que en este trabajo le prestamos atención. El PIB se define como la "suma de los valores monetarios de los bienes y servicios producidos por un país en un año. Para obtener esa suma es necesario evitar que se incurra en una duplicación derivada de las operaciones compra-venta que existen entre los diferentes productores" (INEGI, 1990). EI PIB es la suma del valor agregado en la economía y es uno de los indicadores más imponanies para evaluar la actividad económica, ya sea de un sector, o rama o de toda la economía.

Hablamos del período cuando nos referimos a los años de 1970 a 1990. El período, a su vez, se divide en fases, las cuales pueden durar más de un año. 
CUADRO 3. Producto interno bruto de México y Baja California (a precios constantes de 1978 y en millones de pesos) 1970-1990.

\begin{tabular}{|c|c|c|c|c|c|c|c|}
\hline \multirow[b]{2}{*}{ Años } & \multicolumn{2}{|c|}{ México: } & \multirow{2}{*}{$\begin{array}{l}\text { fndice } \\
\text { a } 1980\end{array}$} & \multicolumn{2}{|c|}{ Baja California: } & \multirow{2}{*}{$\begin{array}{l}\text { Indice } \\
\text { a } 1980\end{array}$} & \multirow{2}{*}{$\begin{array}{l}\% \text { de B.C } \\
\text { en Méxic }\end{array}$} \\
\hline & PIB & TCMA & & PIB & TCMA & & \\
\hline 1970 & 1375452 & & 48.0 & 34528 & & 51.9 & 2.51 \\
\hline 1971 & 1441209 & 4.8 & 50.3 & 37183 & 7.7 & 55.9 & 2.58 \\
\hline 1972 & 1581868 & 9.8 & 55.2 & 37416 & 0.6 & 56.3 & 2.37 \\
\hline 1973 & 1727228 & 9.2 & 60.3 & 40391 & 8,0 & 60.7 & 2.34 \\
\hline 1974 & 1817590 & 5.2 & 63.5 & 43770 & 8.4 & 65.8 & 2.41 \\
\hline 1975 & 1929912 & 6.2 & 67.4 & 45801 & 4.6 & 68.9 & 2.37 \\
\hline 1976 & 2077224 & 7.6 & 72.5 & 47342 & 3.4 & 71.2 & 2.28 \\
\hline 1977 & 2173047 & 4.6 & 75.9 & 49399 & 4.3 & 74.3 & 2.27 \\
\hline 1978 & 2337398 & 7.6 & 81.6 & 55220 & 11.8 & 83.0 & 2.36 \\
\hline 1979 & 2595200 & 11.0 & 90.6 & 59638 & 8.0 & 89.7 & 2.30 \\
\hline 1980 & 2864360 & 10.4 & 100.0 & 66495 & 11.5 & 100.0 & 2.32 \\
\hline 1981 & 3073985 & 7,3 & 107.3 & 74234 & 11.6 & 111,6 & 2,41 \\
\hline 1982 & 3101808 & 0.9 & 108.3 & 79235 & 6.7 & 119.2 & 2.55 \\
\hline 1983 & 2917070 & -6.0 & 101.8 & 75268 & -5.0 & 113.2 & 2.58 \\
\hline 1984 & 2906180 & -0.4 & 101.5 & 73367 & -2.5 & 110.3 & 2.52 \\
\hline 1985 & 2962537 & 1,9 & 103,4 & 70419 & -4.0 & 105.9 & 2.38 \\
\hline 1986 & 2666584 & -10.0 & 93.1 & 71179 & 1.1 & 107.0 & 2.67 \\
\hline 1987 & 2801123 & 5,0 & 97.8 & 71284 & 0.1 & 107.2 & 2.54 \\
\hline 1988 & 2676476 & -4.4 & 93.4 & 71600 & 0.4 & 107.7 & 2.68 \\
\hline 1989 & 2767906 & 3.4 & 96.6 & 72971 & 1.9 & 109.7 & 2.64 \\
\hline 1990 & 2851081 & 3.0 & 99.5 & 75820 & 3.9 & 114.0 & 2.66 \\
\hline
\end{tabular}

FUENTE: 10 Años de indicadores económicos y sociales de México. 1987. INEGI; Agenda estadística. 1989. INEGi; La economía mexicana en cifras, 1988. Nacional Financiera, S.A.; Indicadores económicos. 1990. Banco de México; Estadísticas generales de Baja California. 1983. COPLADE de Baja California; Agenda estadística del municipio de Mexicali, Baja California. 1990. XIII Ayuntamiento de Mexicali.

NOTAS: 1990 es estimado.

Los valores del PIB corrientes se deflacionaron en base a los INPC para México y del IEPC de Baja California.

TCMA: tasa de crecimiento media anual. 
CUADRO 4. Índice nacional y estatal de precios al consumidor. México y Baja California 1970-1990.

\begin{tabular}{lrrrr}
\hline Años & INPC & Anual & IEPC & Anual \\
\hline 1970 & 32.3 & 2.1 & 32.2 & 1.9 \\
1971 & 34.0 & 5.3 & 33.9 & 5.3 \\
1972 & 35.7 & 5.0 & 35.9 & 5.9 \\
1973 & 40.0 & 12.0 & 39.3 & 9.5 \\
1974 & 49.5 & 23.8 & 47.9 & 21.9 \\
1975 & 57.0 & 15.2 & 53.8 & 12.3 \\
1976 & 66.0 & 15.8 & 62.1 & 15.4 \\
1977 & 85.1 & 28.9 & 85.3 & 37.4 \\
1978 & 100.0 & 17.5 & 100.0 & 17.2 \\
1979 & 118.2 & 18.2 & 127.5 & 27.5 \\
1980 & 149.3 & 26.3 & 150.5 & 18.0 \\
1981 & 191.1 & 28.0 & 182.6 & 21.3 \\
1982 & 303.6 & 58.9 & 323.6 & 77.2 \\
1983 & 612.9 & 101.9 & 712.2 & 120.1 \\
1984 & 1014.1 & 65.5 & 1148.2 & 61.2 \\
1985 & 1599.7 & 57.7 & 1819.2 & 58.4 \\
1986 & 2979.2 & 86.2 & 3450.1 & 89.6 \\
1987 & 6906.6 & 131.8 & 8553.9 & 147.9 \\
1988 & 14791.2 & 114.2 & 17345.2 & 102.8 \\
1989 & 17750.6 & 20.0 & 20459.2 & 18.0 \\
1990 & 23850.0 & 34.4 & 27658.2 & 35.2 \\
& & & & \\
\hline
\end{tabular}

FUENTE: Indicadores Económicos (Banco de México), varios números. Las estadisticas registran a las ciudades de Mexicali y Tijuana, para el IEPC se promediaron las dos ciudades por igual. Para 1990: Estimaciones.

INPC: Índice nacional de precios al consumidor, México.

Anual: Porcentaje de inflación anual respecto al año anterior. IEPC: Índice estatal de precios al consumidor, Baja Califormia.

a la entidad que al promedio nacional, con excepción de 1985; y d) parece que la entidad sufre una recesión mayor que la de México.

En la figura 3 se observan claramente los comportamientos de las TCMA del PIB de México y de la entidad, nótese las diferencias significativas en la última fase, dato importante para comprender el contexto de los cambios sociales y políticos que B.C. ha sufrido durante estos años. 
En cuanto a la participación del PIB de B.C. en el nacional podemos anotar lo siguiente: hay un crecimiento constante del porcentaje que termina en 1990 en alrededor del $2.66 \%$, cuando en 1970 era de $2.15 \%$. Por lo tanto, bajo esta línea observamos que los cambios en la participación de la entidad en el PIB nacional no tiene variaciones significativas durante todo el período.

La hipótesis que podemos exponer respecto a los comportamientos del producto interno bruto es que existe un rompimiento estructural en el comportamiento económico entre las dos unidades - México y Baja California- en 1982. Rompimiento que refleja estilos de crecimiento económico diferentes desde entonces. Es en este año donde se puede localizar un cambio importante en la dinámica de la entidad, diferenciado del de México.

Baja California sufre un año de recesión en 1976, situación que no se dio a nivel nacional. El auge económico de 1977 a 1981 es menor en el país que en la entidad, a pesar de que ésta no posee ninguna industria petrolera, pero probablemente la economía bajacalifornia absorbió capitales financieros nacidos durante el auge petrolero.

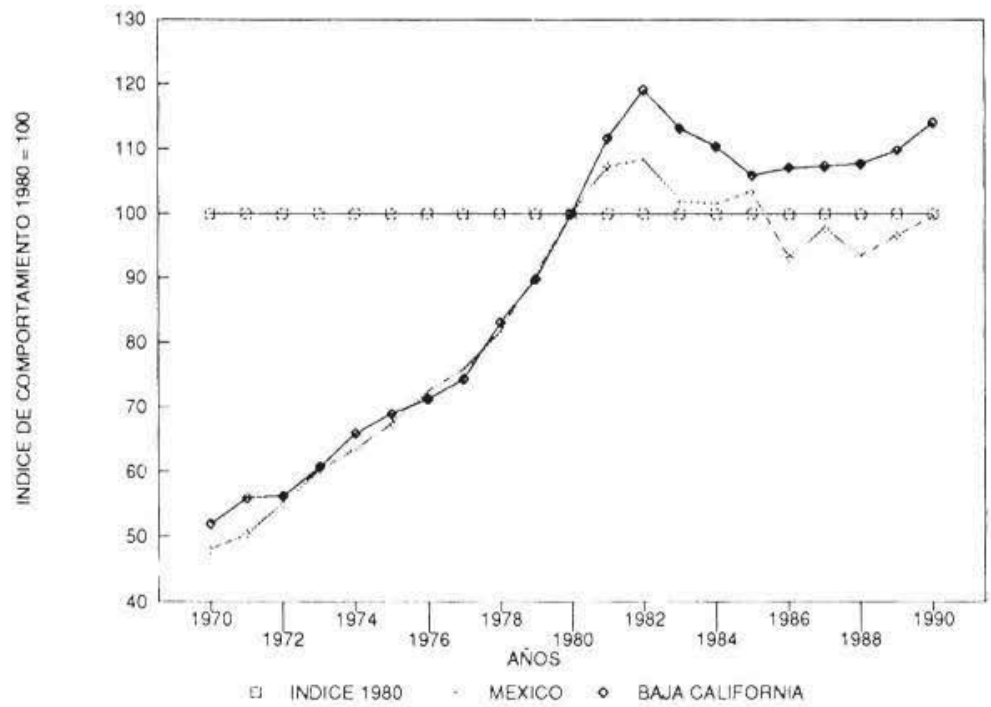

FIGURA 3. Índice a 1980 del PIB, 1970-1990; México y Baja California. 
Además, México vive 4 años de crisis - 1983, 1984, 1986 y 1988-; en cambio Baja California sufre su crisis en una fase comprendida en tres afios seguidos: de 1983 a $1985 .^{7}$

El comportamiento del PIB está ligado indudablemente a la demanda efectiva. ${ }^{8}$ El estudio de la demanda es necesario porque es la forma más importante en que los consumidores, ya sea individuos, empresas o el estado, satisfacen sus necesidades mediante la obtención de bienes y servicios.

Así pues, la demanda efectiva ${ }^{9}$ responde a las fases definidas para el periodo y expresa la capacidad de compra de tres grandes unidades de la sociedad mexicana: del capital, de la fuerza de trabajo y del sector público. Son tres variables componentes de la demanda efectiva: remuneraciones, excedentes de explotación y consumo de gobierno. Lo probable es que, durante la fase de crisis, las remuneraciones y el consumo de gobierno bajen, y se sostengan los índices de los excedentes de explotación.

Muchos estudios demuestran que los cambios en el período son sustanciales para la economía nacional y estatal: la demanda ha cambiado a favor de las inversiones y del capital en contra de las remuneraciones; y que el consumo de gobierno sigue siendo un elemento fundamental para sostener la dinámica económica de las unidades.

Por problemas de las fuentes de información para Baja California, no es posible analizar los cambios de una manera desglosada en los sectores económicos para los años posteriores a $1985 .{ }^{10}$ Pero podemos presentar algunas características de la entidad.

7 Todas las series de valor en este trabajo se presentan a precios constantes de 1978 , debido a que nos interesa detectar los cambios "reales" de ellas. Por su pante, los porcentajes de cambio anual, que expresan los comportamientos coyunturales de las variables, están contemplados en la TCMA. Y, por último, cuando la estadística lo permite, se destaca también la participación de las variables en los totales agregados, con esto definimos los cambios de estilo en el comportamiento de una determinada variable.

\&a demanda global se define como el valor de las compras realizadas por las empresas, las familias y el gobiemo, de los bienes y servicios producidos por la economía más las exportaciones. Se divide en demanda intermedia y final y se compone del consumo total y la inversión bruta total, La oferta global está compuesta por el pts más las importaciones. Por su parte, la demanda efectiva hace referencia a la demanda proveniente de ires unidades: por las inversiones (desde el capital), por la fuerza de trabajo (las remuneraciones) y por el sector público (el consumo de gobiemo). Estas categorias desglosadas expresan más profundamente los cambios ocurridos en el comportamiento económico del país.

La demanda efectiva es de interés ya que se define como el conjunto de bienes y servicios que los consumidores adquieren realmente en el mercado: demuestra la capacidad de compra de una sociedad y, por ende, determina los niveles de la producción social (López, 1987). Desgraciadamente no tenemos los valores de este indicador a nivel estatal, aunque a nivel nacional es parte de las cuentas nacionales.

10 Hasta noviembre de 1989 , el SCNM del INEGI publica el PIB por sectores y ramas económicas a nivel de entidades federativas para el año de 1985, estos datos son estimaciones, lo cual limita nuestro análisis; no existen datos después de 1985 para los sectores económicos del PIB. Véase: Producto interno bruto por entidad federativa NEGt, 1989. México. 
En cuanto a los porcentajes de participación de los sectores en el PIB para 1985 resaltan los siguientes hechos: poca participación de la minería en la entidad; en la industria manufacturera - esta categoría no contempla la "industria maquiladora"- es menor su participación relativa en la entidad que en la nacional, pero mayor en construcción y más en comercio, restaurantes y hoteles y en el sector de servicios comunales y personales.

Esta situación demuestra las diferencias relativas en los modelos de comportamiento de México y Baja California: la entidad se inclina por las actividades económicas del sector terciario, aunque el sector primario y secundario juegan un papel importante y éstos no se alejan mucho de las pautas nacionales, principalmente el sector secundario.

Parece como si las diferencias entre la entidad y el país están "compensadas": la baja participación en PIB de la entidad en el sector I (actividades primarias), comparada con la participación del mismo a nivel nacional, se compensa por la alta participación del sector m (actividades terciarias) en el PIB de B.C. Estas diferencias son las que denotan los estilos de crecimiento diferentes de las dos unidades,

Los modelos de comportamiento de México y Baja California son diferentes, pero no tanto como muchos autores afirman. La mayoría de ellos han tratado de definir el modelo de comportamiento de la entidad en base a que éste es un "modelo terciarizado", aquí planteamos más bien que las principales diferencias de la entidad respecto a las medias nacionales se encuentran más en el sector externo y en las características de una economía fronteriza que en la estructura productiva de la entidad.

En efecto, la idea de que el modelo de crecimiento de la entidad se encuentra "terciarizado" se puede encontrar en Carrillo, 1980; Mendoza, 1981; Lloréns, 1983; Ramírez, 1983; Carrillo et al., 1986; Sández, 1987; y Siqueiros, 1987.

La terciarización de la economía de B.C. “....se ha debido probablemente a la combinación de dos características singulares del estado. Una, que tres de los cuatro municipios que forman el estado son fronterizos; la otra, que en el estado ha imperado durante décadas el régimen de zona libre." (Carrillo, 1980: 85). Pero el mismo autor había señalado antes que "la estructura de la actividad económica del estado ha cambiado notablemente en años recientes; ha pasado de ser una economía especializada en las actividades terciarias (comercio y servicios) a una economía no especializada" (Carrillo, 1980: 73). Entonces, una economía no especializada no puede ser definida como un modelo de crecimiento terciarizado.

Más bien pensamos que si se toman los datos de 1970 del PIB desglosado en los nueve sectores económicos, efectivamente se observa una economia con tendencias predominantes a las actividades terciarias; pero 
si se toma el desglose del PIB en los tres grandes sectores aparece una tendencia lenta hacia la baja porcentual en ese sector.

Así, "Las mayores discrepancias [entre la entidad y México] tanto en el valor censal bruto de la producción como en la población económicamente activa, se presentaron en los servicios. Los servicios determinan, a su vez, muy marcadas características sociales y culturales de la población fronteriza" (Mendoza, 1981: 54).

La idea sustancial del modelo de crecimiento terciarizado de la entidad tiene sus antecedentes históricos explicables porque "desde los inicios del poblamiento acelerado de la segunda década del presente siglo, la economía bajacaliforniana fue respuesta a la expansión norteamericana, económica y demográficamente hacia el suroeste. Bajo esta condición se consolidó una economía agrícola y de servicios fuertemente vinculada a los Estados Unidos" (Lloréns, 1983; 52). Por lo tanto, aquí destaca la incapacidad de la entidad para generar áreas económicas industriales y mecanismos de vinculación con el resto del país.

Así, "el modelo de crecimiento económico que ha caracterizado a Baja California en los últimos 50 affos, es un modelo completamente diferente al adoptado por el resto del país en su intento de industrialización" (Ramírez, 1983; 29). Pues mientras la entidad crecía económicamente bajo el esquema de la importación libre de bienes, en el país se impulsaba el proteccionismo al mercado interno.

El pilar del crecimiento terciarizado en la entidad ha sido, según estos autores, la existencia del régimen de zonas y perímetros libres.

La misma idea implica que "la economía del estado presenta una estructura productiva altamente terciarizada, donde convive paralelamente una actividad primaria altamente inestable que implica cuellos de botella en la provisión de insumos para el sector manufacturero" (Carrillo, et al. 1986: 65). Aquí se relaciona la economía terciarizada con la insuficiencia del desarrollo industrial. ${ }^{12}$

\footnotetext{
11 El autor dice que "El estado de Baja Califomia, sin ser ajeno a la problemática nacional, manifiesta en su vida económica características propias, entre las que destacan: 1) la lejanía de los centros de producción nacionales, lo que implica ciertos problemas para su absstecimiento; 2) el notable aumento de su población con sus secuelas de desocupación y hacinamiento en las ciudades; 3) un desarrollo industrial insuficiente para atender las demandas domésticas; y 4) una alta propensión a la importación, de lo que se deriva una amplia dependencia con el exterior" (Ramírez, 1983:29).

12 En efecto, siguiendo con la línea expuesta en la nota anterior, los autores afiman que "Por lo que corresponde a su estructura económica, 1) presents una acentuada especialización en el comercio y servicios turísticos; 2) con un sector primario que ha perdido dinamismo, $y ; 3$ ) un crecimiento industrial insuficiente donde predomina la pequeña y mediana industria de lo cual se deriva una incapacidad para atender las demandas domésticas" (Camillo, et al., 1986; 5 y 6).
} 
Para otro autor, el crecimiento de la "industria maquiladora - que impone barreras de entrada a la industria de transformación y genera un crecimiento económico sin desarrollo industrial en la entidad-así como el reducido mercado local — cuyos patrones de compra se orientan históricamente a la importación - inciden en la acentuada terciarización de la actividad fronteriza" (Sández, 1987:17). Este autor escribe que la economía terciarizada de la entidad es también debido a la existencia del régimen fiscal de excepción de la zona libre y la presencia importante del sector maquilador (Sández, 1987: 71-72).

Entonces, la presencia de la zona libre "configura un modelo distinto de economía respecto al resto del país, donde la creciente importancia de las actividades comerciales de la entidad viene a explicar la terciarización en la actividad económica de Baja California" (Siqueiros, 1987:26). Aunque la idea de una creciente predominancia de las actividades comerciales en la entidad no se confirma. ${ }^{13}$ En resumidas cuentas: "De acuerdo con la evolución de la estructura económica de la entidad, el proceso de conformación seguido por el modelo nacional adoptado como alternativa de desarrollo por vía de la sustitución de importaciones, no fue aplicado para Baja California [...] lo que ha ocasionado que la estructura productiva actual presente características distintas a las del resto del país." (Cabrera, 1987; 18).

Aquí planteamos la hipótesis de que el modelo de comportamiento de la entidad es diversificado y semiterciarizado; que éste modelo ha sufrido importantes cambios desde las crisis de 1976 y 1982; que la existencia de la zona libre actualmente no es producto del "distanciamiento" de la entidad respecto al resto del país, pues los medios de transporte masivo ya eliminaron, quizá desde hace tiempo, esta realidad; por tanto, que el modelo de comportamiento de la entidad es de industrialización primaria ${ }^{14}$ y semiterciarizada, e interdependiente con el exterior.

${ }^{13}$ Las peculiaridades o especificidades del modelo de crecimiento de la entidad son cuatro para este autor: "a) existe una alta concentración poblacional en pocos centros urbanos; b) es una región poco integrada a la economía mexicana y sumamente interdependiente con los estados fronterizos de los Estados Unidos; c) es una región cuya estructura productiva está limitada por la oferta, tanto en cantidad como en diversidad, pues su actividad económica descansa en el sector terciario [...] y d) es uns región con importantes carencias urbanas en materia de infraestructura y servicios públicos" (Siqueiros, 1987: 7).

${ }^{14}$ Nos referimos a una industria primaria en cuanto a la industria de transformación. La entidad actualmente cuenta con una industria productora de bienes de consumo básico de bastante amplitud e importancia, Es decir, en términos de fases clásicas de crecimiento, la entidad se encuentra en la sustitución de bienes de consumo inmediato y no ha ingresado a la sustitución de bienes de consumo duraderos, a excepción de las ramas de muebles y construcción. Para mayor referencia al respectó véase la investigación de Sández (1987). Así, "La actividad histórica económica, al ígual que la actual, está relacionada directamente con la producción de bienes básicos que, a su vez, ha llevado a que se cree una actividad económica residente" (Ladman y Duffy, 1986; 189). 
El modelo de crecimiento de la entidad es en realidad el producto de dos vías de crecimiento que actualmente conviven, se relacionan, se contradicen y se combinan: una via, predominantemente relacionada con las características de la frontera norte de México, vinculada al régimen de zona libre, a la agricultura y pesca de exportación y promoción al turismo; es decir, a las especificidades geográficas y de mercado internacional.

La otra vía es aquélla que dirige sus actividades en función del mercado local y nacional: crecimiento de la industria de transformación y aumento en las relaciones con el comercio nacional, principalmente. Históricamente las dos vías de crecimiento se iniciaron en una misma época: la década de los treinta (Lloréns, 1983: 53-54).

A nivel nacional, desde la década de los cuarenta se definieron dos regímenes fiscal-arancelarios, "diferenciados espacialmente y frecuentemente contradictorios: el nacional proteccionista (derivado de la estrategia de sustitución de importaciones) y el fronterizo liberal" (Tamayo, 1988: 134). Hoy en día, con la promoción del Acuerdo de Libre Comercio de México, Estados Unidos y Canadá estas características no serán exclusivas de la entidad, pero ésta seguirá profundizando sus relaciones de interdependencia debido a su ubicación geográfica y a su experiencias en actividades económicas de libre mercado.

Por lo tanto, dado los sucesos en los años posteriores a 1982, la economía de la entidad asume una nueva modalidad y un estilo de crecimiento diferente respecto al PIB nacional; denotando así una "ruptura relativa" en las tendencias de crecimiento de la entidad respecto a las de México y creando bases mejor consolidadas para hacer frente a los procesos devaluatorios y a la liberación de los mercados entre México y los Estados Unidos.

La perspectiva, en este sentido, es un crecimiento con una mayor vulnerabilidad, ${ }^{15}$ pues posiblemente ya no se encuentren las fuentes de crecimiento en las inversiones directas extranjeras, ni en el comercio exterior, sino en las fuentes de financiamiento externo, en la esfera del crédito y de los movimientos đel capital (López, 1978:14).

Y a nivel nacional la perspectiva de un cambio en el modelo de comportamiento tendría sus "rasgos esenciales [...] en los siguientes puntos:

\footnotetext{
15 "...algunas implicaciones que para el comercio exterior y el crecimiento se desprenden del hecho de tener una estructura industrial no integrada, es decir, de la ausencia de un sector que produzca bienes de capital [en México]... El análisis parte del hecho de que bajo estas condiciones la inversión tiende a autoderrotarse, ya que no crea demanda efectiva ul misme tiempo que aumenta la capacidad productiva. Se argumenta que la altemaliva de aumicntar la demanda de manera exógena conduce también al estancamiento métiante su incidencia negativa sobre la balanza comercial." (Casar y Ros, 1984:75, subrayado nicestro),
} 
a) énfasis en las ramas industriales más pesadas, de bienes intermedios y de capital, en las cuales se daría un avance importante respecto a su actual nivel de sustitución de importaciones; b) caída del salario real, aumento del desempleo abierto y del grado de monopolio. En suma, redistribución regresiva del ingreso; c) gran apertura externa y fuerte expansión de las exportaciones manufactureras" (Valenzuela, 1986:166). ${ }^{16}$ Rasgos que muy posiblemente se profundicen en la entidad en un futuro cercano.

\section{LOS PROBLEMAS BÁSICOS DE LA ECONOMÍA}

Uno de los síntomas más graves de la crisis, inaugurada en serio desde 1982, ha sido la inflación que ha sufrido el país. Ésta puede explicarse, entre otras causas, por tres razones: 1) por el incremento de precios internacionales de los bienes de capital importados; 2 ) el atiborramiento por parte del Estado de los canales de circulación de papel moneda y créditos; $y, 3$ ) el incremento de los costos de operación dél aparato productivo como un mecanismo de defensa en las tasas de ganancia." (López D., 1978:24).

La inflación en Baja California ha sido también un problema, concretamente durante los años de fuertes devaluaciones; esta situación de hecho ha borrado en ocasiones la "ventaja comparativa" que los productos de la entidad tenían respecto a los precios internacionales y que facilitaban su consumo por parte de la población fronteriza (Muro, 1986).

En términos generales se puede decir que la crisis y la recesión en México han implicado costos sociales en los niveles de vida de la población debido a "1) la creciente pérdida del poder adquisitivo, 2) la inflación, 3) la devaluación del peso frente a las monedas internacionales, 4) la fuga de capitales, 5) el desempleo y 6 ) la ređucción de los servicios públicos." (Oswald, 1987; 31). En este contexto se estima que los niveles de vida en los últimos años de los ochenta se encontraban igual que en los primeros años de los setenta. Consideramos a la inflación y la devaluación como variables importantes para comprender los ajustes que sufre la economía de la entidad desde 1976, y más concretamente desde 1982 a la fecha.

\footnotetext{
16 “el país ya empezó a avanzar hacia un nuevo patrón de acumulación, y éste noes otro que el secundario exportador, ya imperante en el cono sur. En el caso mexicano, cabe esperar algunos matices o variantes: las semejanzas serán mayores con Brasil y las diferencias más grandes en relación a, por ejemplo, Chile. En esto no sólo influyen las dimensiones o tamaño del país, de modo fundamental, los aspectos sociopolíticos. En México cabe esperaruna dosis más elevada de pragmatismo, una intervención estatal más alta y cierta 'suavidad ' política en la transición. Es decir, los quiebres institucionales de gran magnitud ocurridos en el cono sur muy probablemente sean obviados en el caso que nos preocupa." (Valenzuela, 1986:166). El Tratado de Libre Comercio de 1991 confirma casi plenamente estas hipótesis.
} 
Sin duda alguna, la inflación ${ }^{17}$ y los procesos devaluatorios tienen efectos específicos y más pronunciados en la economía de la entidad que en el resto del país. En los cuadros 4 y 5 presentamos sus valores; para el primer caso el índice y para el segundo, los pesos por dólar. La inflación en México "es regresiva en su efecto en la distribución del ingreso. Esto lo aceptan las autoridades y lo señalan los especialistas y el saber popular" (Cervantes, 1982; 695).

Desde 1976 y, principalmente desde 1982, los cambios del sistema de precio en México tienen sus causas fundamentales en los sectores internos y externos de la economía: 1) debido a los desequilibrios de la balanza de pagos y comercial con el exterior —como se vera más adelante-;2) al proceso del endeudamiento externo como mecanismo de acumulación; y, 3) a los desequilibrios del aparato productivo y monetario, principalmente la caída del sector agropecuario y la serie de problemas que sufre el modelo de crecimiento económico mexicano.

Los precios de los bienes y servicios en México se ven también influidos por los precios internacionales, principalmente aquéllos que defineu los precios del petróleo, materias primas y alimentos. A los precios internos se añaden los cambios de precios internacionales dado el alto contenido de importaciones de bienes manufactureros y de capital (Perzabal, 1987:262).

Este mecanismo - en donde los precios internos se ven arrastrados por los precios internacionales - adquiere una dimensión especial durante la fase del auge por el excesivo endeudamiento, los cambios de los precios internacionales y el fuerte desequilibrio de la balanza de pagos.

Para la entidad, el arrastre de los precios externos sobre los internos es mayor que en el resto del país. En el cuadro 4, se puede apreciar cómo en los años de fuertes devaluaciones, el proceso inflacionario de la entidad es considerablemente mayor que el nacional: 1977, 1983 y 1987 con una acumulación mayor del índice. En la figura 4, se aprecian claramente estos comportamientos diferenciados de la inflación.

La inflación, como la devaluación, se encuentra ligada directamente al comportamiento del sector externo.

${ }^{17}$ En general, "La inflación es un fenómeno en el que se manifiestan las desproporcionalidades en el funcionamiento general de la economía, entre los sectores productivos y el de servicios, entre las cuentas externas y la producción y productividad interna y en la pérdída de proporcionalidad en la redistribución de la ganancia social. La inflación es también un fenómeno monetario, es decir, un aumento extraordinario de los precios, desproporcionado con los aumentos en los costos de producción y con la cantidad de dinero en circulación, desproporcionada respecto de la magnitud del valor de las mercancias." (Perzabal, 1987:267 y 268). 
CUADRO 5. Tipo de cambio pesos por dólar 1970-1990.

\begin{tabular}{lrrr}
\hline Affos & T.C. & TCMA & Indice 1980 \\
\hline 1970 & 12.50 & & \\
1971 & 12.50 & 0.00 & 54.47 \\
1972 & 12.50 & 0.00 & 54.47 \\
1973 & 12.50 & 0.00 & 54.47 \\
1974 & 12.50 & 0.00 & 54.47 \\
1975 & 12.50 & 0.00 & 54.47 \\
1976 & 15.69 & 25.52 & 54.47 \\
1977 & 22.69 & 44.61 & 68.37 \\
1978 & 22.76 & 0.31 & 98.87 \\
1979 & 22.82 & 0.26 & 99.17 \\
1980 & 22.95 & 0.57 & 99.43 \\
1981 & 24.51 & 6.80 & 100.00 \\
1982 & 57.31 & 133.82 & 106.80 \\
1983 & 135.23 & 135.96 & 249.72 \\
1984 & 176.48 & 30.50 & 589.24 \\
1985 & 283.62 & 60.71 & 768.98 \\
1986 & 624.62 & 120.23 & 1235.82 \\
1987 & 1386.27 & 121.94 & 6040.39 \\
1988 & 2269.93 & 63.74 & 9890.76 \\
1989 & 2468.28 & 8.74 & 10755.03 \\
1990 & 2823.23 & 14.38 & 12301.66 \\
& & & \\
\hline & & &
\end{tabular}

FLENTE: Indicadores eccóómicos. Banco de México.

TC. = Tasa de cambio, como promedio del año, de 1982 en adelante es el promedio del dólar controlado y el libre.

TCMA. Tasa de crecimiento media anual.

Indice 1980: Indice de comportamiento base $1980=100$.

El cambio del valor del peso respecto al dólar altera significativamente los precios de los bienes y servicios que se imputan en moneda extranjera, principalmente en dólares. Los precios de los bienes y servicios que se importan aumentan en términos de la moneda nacional y tienden a una significativa reducción en su volumen. En cambio, los precios de los bienes y servicios que se exportan alteran su precio, pero a favor de la moneda nacional, su volumen tiende a creecr. 
De esta forma, teóricamente, con las devaluaciones la brecha entre el valor de las exportaciones e importaciones totales tiende a cerrarse con el correspondiente "mejoramiento" de la balanza de pagos. En México, dicho equilibrio se estableció más por el lado de la reducción del volumen de las importaciones que por el aumento en las exportaciones.

A lo largo de 1970 a 1982 se puede asegurar que el peso mexicano estuvo en "promedio" sobrevaluado. La primera devaluación se inició en $1976,{ }^{18}$ en ésta fue evidente que los componentes de la demanda total se vieron afectados; aunque la caída de la inversión fue más evidente lo cual implicó una primera crisis coyuntural del país después de varios años de franco crecimiento. Posteriormente, se inicia un constante desajuste de la paridad peso-dólar (ver cuadro 5 y figura 5).

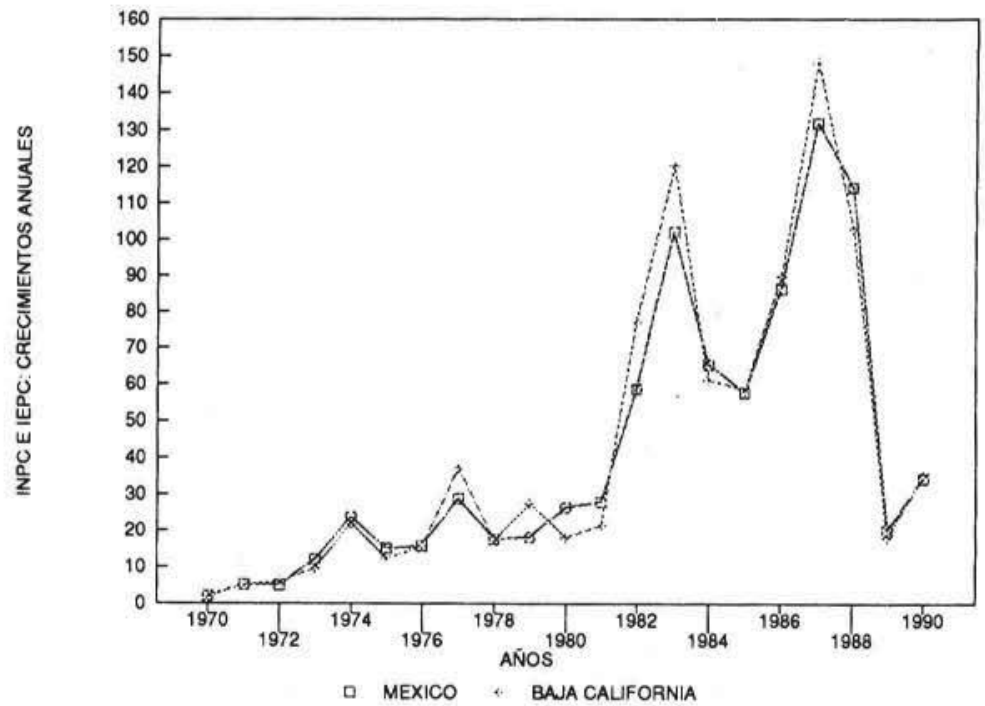

FIGURA 4. Índice anual de INPC e IEPC 1970-1990; México y B. C.

18 "El 31 de agosto de 1976, en vista del creciente éxodo de capitales, el secretario de Hacienda anunció que se abandonaba la paridad fija que estaba vigente desde 1954. Se dejaría que el peso flotara en relación al dólar a fin de que el mercado determinara su 'valor de equilibrio'. El tipo de cambio se elevó a 20-21 pesos por dólar y el Banco de México comenzó a manejar una reducción gradual de la relación peso-dólar decretando una paridad temporal de 19.70-19.90 pesos por dólar." (Córdoba y Ortiz, 1980:298). 


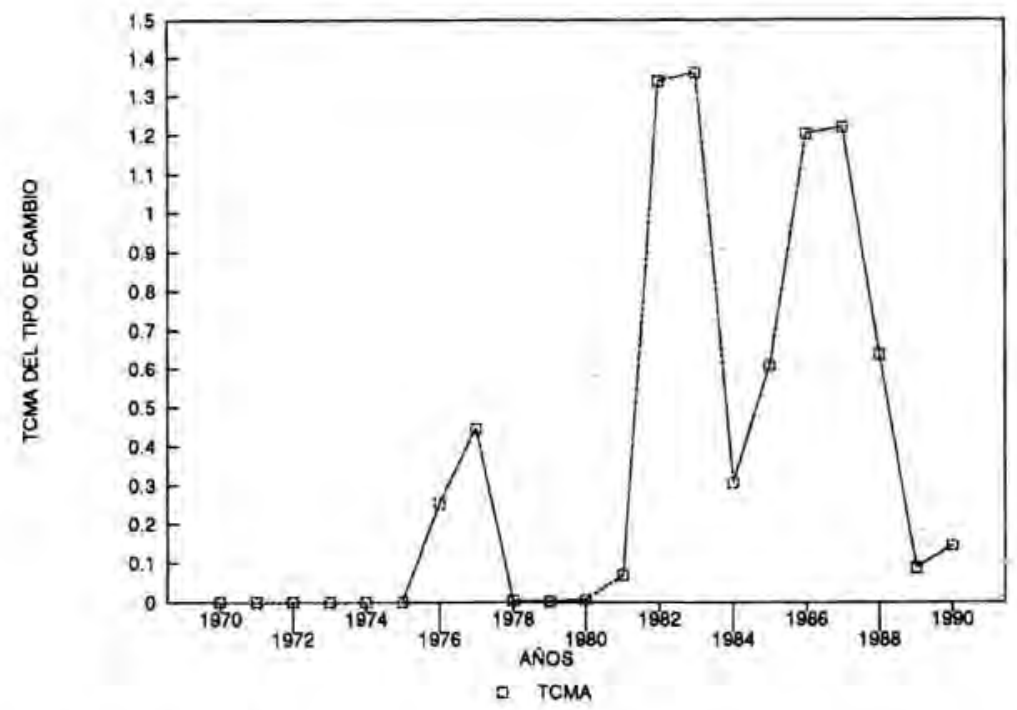

FIGURA 5. TCMA del tipo de cambio 1970-1990 (pesos por dólar).

Los años de sobrevaluación del peso constituyen un mecanismo de "subsidio" a las importaciones; en cambio la subvaluación es un "subsidio" a las exportaciones. Estos comportamientos son de estratégico valor para el consumo importado fronterizo, ya que una gran parte del consumo total se genera por importaciones, y mientras éstas se encuentren con un tipo de cambio sobrevaluado, permiten aumentar las tasas de consumo promedio de la población en general.

Es decir, para la entidad, la relación peso-dólar es de vital importancia, ya que una parte importante del consumo de la población se realiza con moneda extranjera. De ahí que "dentro del conjunto de importadores mexicanos subsidiados en el período en cuestión... (1970-1975 y 1977 1981) se contó muy principalmente la población fronteriza del norte de México, importadora tradicional de buena parte de sus bienes de consumo" (Tamayo, 1982:155-156).

Los aflos de sobrevaluación son de 1970 a 1975 . Posteriormente, en 1976, existe un ajuste más o menos equilibrado. Para 1977 a 1981 se tiende también a una nueva sobrevaluación, pero no tan profunda como al inicio de la década de los setentas. Después de 1982, el peso mexicano aparece permanentemente subvaluado, con un ajuste importante en 1986 y 1988. 
Una creciente sobrevaluación del peso hizo que, a principios de los años setenta, algunos de los comercios fronterizos norteamericanos se volvieran dependientes de consumidores fronterizos mexicanos. ${ }^{19} \mathrm{Las}$ devaluaciones de 1982 indudablemente fueron las más graves: un cambio de valor equivalente al $245 \%$, el mayor durante todo el período y el peor año para la economía y la población fronteriza. ${ }^{20}$ Quizás las devaluaciones de 1986 y 1987 no impactaron tan negativamente a la entidad, en mucho debido no sólo a que fueron menores a las de 1983, sino también a la "experiencia acumulada" de los agentes económicos fronterizos para hacer frente a este tipo de contingencias.

Desde 1982, el comercio fronterizo incrementó la oferta de mercancías nacionales, pues repentinamente tenía que sustituir los bienes importados por bienes nacionales para satisfacer el traslado de la demanda externa hacia la interna. Varios estudios estiman que las ventas nacionales en la frontera crecieron de 35 a $40 \%$, por ejemplo en Tijuana (Ramírez y Mungaray, 1985:10). El encarecimicnto de las importaciones se acompañó también de políticas restrictivas de la inversión pública - como lo veremos mas delante- y por una fuerte contracción de la economía en general.

Entonces, a partir de 1982 el estancamiento del sector externo implicó de hecho la devaluación del peso, que en gran medida afectó el nivel de consumo importado especialmente para la población fronteriza. Esto se explica porque "la economía fronteriza mexicana [...] por necesidad utiliza la divisa como medio de pago y por lo tanto las fluctuaciones en las variables económicas mexicanas, - principalmente en el tipo de cambio-implican un shock en el corto plazo" (Carrillo, 1983:30). ${ }^{21}$

\footnotetext{
${ }^{19}$ La devaluación de 1976 implicó serios ajustes en las relaciones comerciales fronterizas. Una amplia descripción periodística de los hechos ocasionados por la devaluacíón de 1976 en la frontera norteamericana aparece en el texto de Barrera y Melesio (1979).

20 En efecto, para la frontera "en sólo ocho meses, entre febrero y septiembre de 1982, la vida de casi tres millones de mexicanos - habitantes de los 36 municipios fronterizos del norte del país - dio un giro de 180 grados y súbitamente pasó de la opulencia a la crisis. De pronto, su poder adquisitivo cay6 en casi $700 \%$ y se enfrentaron a un proceso de devaluación-inflación-especulación y desabasto de antículos de primera necesidad, cuyos efectos todavía no se superan" (Muro, 1986).

21 En términos de la demanda de la frontera norte de México se pueden esperar tres efectos fundamentales de las devaluaciones: 1) que la población fronteriza de ingresos nacionales y con altos porcentajes de gastos extemos cambien su patrón de gasto a favor de mercancías y bienes nacionales; 2) que la población fronteriza con ingresos extemos y gastos intemos aumenten su consumo de bienes y servicios mexicanos; y 3 ) que la población fronteriza norteamericans aumente sus compras de bienes y servicios del lado mexicano. Todo ello suponiendo una oferts nacional suficiente y adecuada en la frontera norte de México (Carrillo, 1983:32).
} 
Es claro que las devaluaciones en las fases de crisis y recesión han implicado fuertes cambios para los ingresos y egresos de las empresas y las familias, en general, de Baja California: ${ }^{22}$ la reducción drástica de la oferta de dólares para laeconomía de la entidad implica cambios sustanciales en el costo de producción y de comercialización de los bienes y servicios y también implica cambios en los patrones de ingresos y gastos de las familias.

Las modificaciones en el patrón de consumo de la población fronteriza, debido a las devaluaciones y al proceso inflacionario, es un dato que acompaña desde 1982 al panorama de la economía de la entidad.

Esta última situación a nivel nacional es detectada en la encuesta "100 días en el consumo familiar" elaborada por el INCO (Instituto Nacional de Consumidor, 1984) donde el resultado fue que las familias mexicanas gastan más en comida pero con una peor alimentación.

Entre las estrategias que han implementado las familias de la entidad para hacer frente al deterioro que implican las devaluaciones y la inflación destacan: 1) emigración laboral hacia los Estados Unidos de un miembro o más de la familia; 2) cambios en el patrón de consumo a favor de bienes y servicios nacionales; 3 ) aumento del número de personas por familias y hogares en la población económicamente activa y, 4) se generan ingresos extras a través de la llamada "economía informal".

Otra problemática vital para la economía de Baja Califomia es el sector externo. En la mayoría de los países éste cumple una función fundamental en cuanto que contiene las relaciones económicas con el resto del mundo; igualmente ocurre en México ya que es parte de la dinámica del crecimiento y de la crisis.

En los cuadros 6 y 7 se anotan -resumidamente- los ingresos y egresos totales de la balanza de pagos de la cuenta conriente de México de 1970 a 1990 en millones de dólares corrientes junto con la variable de las transacciones fronterizas. También en las figuras 6 y 7 presentamos los índices de comportamiento base $1980=100$ de estas variables del sector externo para tener una idea más clara de cuales han sido sus principales movimientos.

En cuanto al cuadro 6 podemos observar un aumento exagerado de los ingresos totales del sector externo de México durante la fase de auge y una caída profunda durante 1985 y 1986, con una recuperación posterior. Las transacciones fronterizas persiguen, de alguna manera, al total de ingresos, sólo que tienen movimientos más bruscos.

En el caso de los ingresos por transacciones fronterizas en Baja California, desde 1981 hay una franca caída que se recupera apenas con

22 Por estas razones, Tamayo (1982:154) indica que las crisis nacionales en sus líneas generales tienen un "reflejo frecuentemente ampliado" en la frontera norte de México" 
un 25\% mayor a 1980. En estos indicadores, existen TCMA negativas en aquellos anos donde los problemas del tipo de cambio han sido agudos, lo que viene a confirmar la idea de que las devaluaciones por sí mismas no generan mayores ingresos del exterior.

En cuanto a los egresos, que expresa la capacidad de consumo de las regiones en el exterior, podemos señalar algunos datos interesantes según se puede apreciar en el cuadro 7 y su respectiva figura.

También los egresos tienden a aumentar más que los ingresos en la fase de auge; posteriormente su caída es mayor que en los ingresos, pero con la salvedad de que en la fase de recesión terminan con índices de comportamiento mayores que su movimiento inverso: $31 \%$ en ingresos totales, $61 \%$ en transacciones fronterizas y $130 \%$ en éstas mismas para Baja California en base a 1980.

El resultado del comportamiento de los ingresos y egresos del sector externo nos da una idea muy cercana de los cambios que sufren las importaciones y las exportaciones. Recordemos que para la entidad las importaciones de bienes son un elemento sustancial en los insumos del aparato económico y del consumo de la población, aunque sin duda alguna cada vez menos.

En el cuadro 8 se observan los resultados en las balanzas respectivas: total para México, para las transacciones fronterizas de la región y para Baja California y las balanzas comerciales (exportaciones menos importaciones).

Al respecto, baste señalar que la balanza total del país pocas veces ha sido positiva, sólo en aquellos affos cuando la crisis semiparaliza el sector se logran balanzas positivas (de 1983 a 1985) a costa de reducciones drásticas en las importaciones, y de ninguna manera por aumento en las exportaciones. Sin duda alguna, aunque la balanza comercial mexicana desde 1982 es positiva, la balanza total sigue siendo deficitaria debido al pago de la deuda externa.

Por su parte, las transacciones fronterizas son deficitarias desde 1980, contribuyendo al déficit general. Es interesante hacer notar que la balanza comercial de Baja California permanentemente ha sido deficitaria, y que su valor más alto se encuentra precisamente un año antes de la crisis de 1982. En la figura 8 se presentan los déficit de las transacciones fronterizas y la balanza para la entidad.

Resumiendo: destaca la tendencia a la baja del valor de las exportaciones de la entidad en el período, con excepción de 1976, 1982 y 1986-1987, es decir en los años de fuertes devaluaciones. En cuanto a las importaciones es interesante hacer notar que su crecimiento en 1982 es 5 veces más que en 1970. Por su parte, los ingresos fronterizos se comportan de una forma 
CUADRO 6. Ingresos totales del sector externo de México y transacciones fronterizas (en millones de dólares corrientes) 1970-1990.

\begin{tabular}{|c|c|c|c|c|c|c|c|c|c|}
\hline \multirow[b]{2}{*}{ Años } & \multicolumn{2}{|c|}{ México: } & \multirow{2}{*}{$\begin{array}{c}\text { Indice } \\
1980\end{array}$} & \multicolumn{2}{|c|}{ Frontera norte: } & \multirow{2}{*}{$\begin{array}{c}\text { fndice } \\
1980\end{array}$} & \multicolumn{2}{|c|}{ Baja California: } & \multirow{2}{*}{$\begin{array}{c}\text { fndice } \\
1980\end{array}$} \\
\hline & In. tot. & TCMA & & In. tf. & TCMA & & In.tf. & TCMA & \\
\hline 1970 & 3254.1 & & 14.52 & 1050.1 & & 69.07 & 325.5 & & 62.97 \\
\hline 1971 & 3532.7 & 8.56 & 15.77 & 1176.2 & 12.01 & 77.36 & 341.1 & 4.78 & 65.98 \\
\hline 1972 & 4280.3 & 21.16 & 19.10 & 1313.3 & 11.66 & 86.38 & 397.9 & 16.66 & 76.98 \\
\hline 1973 & 5406.3 & 26.31 & 24.13 & 1526.4 & 16.23 & 100.39 & 477.8 & 20.06 & 92.42 \\
\hline 1974 & 6838.4 & 26.49 & 30.52 & 1650.3 & 8.12 & 108.54 & 533.0 & 11.57 & 103.12 \\
\hline 1975 & 7135.6 & 4.35 & 31.85 & 1925.3 & 16.66 & 126.63 & 621.9 & 16.66 & 120.30 \\
\hline 1976 & 8277.6 & 16.00 & 36.94 & 2266.8 & 17.74 & 149.09 & 702.7 & 13.00 & 135.94 \\
\hline 1977 & 9177.7 & 10.87 & 40.96 & 2076.8 & -8.38 & 136.60 & 629.3 & -10.45 & 121.73 \\
\hline 1978 & 11653.9 & 26.98 & 52.01 & 2364.2 & 13.84 & 155.50 & 756.5 & 20.23 & 146.35 \\
\hline 1979 & 16264.8 & 39.57 & 72.59 & 2919.3 & 23,48 & 192.01 & 972.1 & 28.49 & 188.05 \\
\hline 1980 & 22406.2 & 37.76 & 100.00 & 1520.4 & -47.92 & 100.00 & 516.9 & -46.82 & 100.00 \\
\hline 1981 & 28014.1 & 25.03 & 125.03 & 1559.4 & 2.57 & 102.57 & 545.7 & 5.56 & 105.56 \\
\hline 1982 & 28003.4 & -0.04 & 124.98 & 1237.7 & -20.63 & 81.41 & 426.3 & -21.88 & 82.47 \\
\hline 1983 & 28944.3 & 3.36 & 129.18 & 1104.2 & -10.79 & 72.63 & 347,8 & -18.41 & 67.28 \\
\hline 1984 & 32902.1 & 13.67 & 146.84 & 1329.5 & 20,40 & 87.44 & 432.1 & 24.23 & 83.58 \\
\hline 1985 & 30774.4 & -6.47 & 137.35 & 1180.6 & -11.20 & 77.65 & 395.5 & -8.47 & 76.51 \\
\hline 1986 & 24170.2 & -21.46 & 107.87 & 1197.9 & 1.47 & 78.79 & 365.4 & -7.62 & 70.68 \\
\hline 1987 & 30568.6 & 26.47 & 136.43 & 1223.1 & 2.10 & 80.45 & 407.9 & 11.64 & 78.91 \\
\hline 1988 & 32589.9 & 6.61 & 145.45 & 1449.8 & 18.53 & 95.36 & 500.2 & 22.62 & 96.76 \\
\hline 1989 & 36584.7 & 12.26 & 163.28 & 1812.2 & 25.00 & 119.19 & 636.5 & 27.25 & 123.13 \\
\hline 1990 & 39120.0 & 6.93 & 174.59 & 1890.8 & 4.34 & 124.36 & 649.4 & 2.03 & 125.62 \\
\hline
\end{tabular}

FUENIE: "10 años de indicadores económicos y sociales de México." 1987; "Agenda estadística", 1989; Indicadores económicos, varios números. Banco de México; La economía mexicana en cifras, 1988. Nacional Financiera, S.A.; Informes de gobierno, anexos estadísticos, Varios años. Gobiemo del estado de Baja California.

1990: Estimaciones. In. tot.: Ingreso total del sector externo mexicano. In. tf.: Ingresos del sector externo por concepto de transacciones fronterizas, para la zona y perimetros libres, y para Baja California.

TCMA: Tasa de crecimiento media anual.

fndice 1980: Indice de comportamiento base $1980=100$. 


\section{CUADRO 7. Egresos totales del sector externo de Mexico y transacciones fronterizas (en millones de dólares corrientes) 1970-1990.}

\begin{tabular}{rrrrrrrrrrr}
\hline \multicolumn{1}{c}{ México: } & \multicolumn{2}{c}{ Indice } & \multicolumn{2}{c}{ Frontera none: } & Indice & Baja California: & Indice \\
Años & Eg. tot. & TCMA & 1980 & Eg. Tf. & TCMA & 1980 & Eg.Tf. & TCMA & 1980 \\
\hline & & & & & & & & & \\
1970 & 4442.0 & & 13.40 & 828.3 & & 41.03 & 289.9 & & 56.07 \\
1971 & 4461.2 & 0.43 & 13.46 & 868.4 & 4.84 & 43.02 & 317.0 & 9.35 & 61.32 \\
1972 & 5286.3 & 18.50 & 15.95 & 939.4 & 8.18 & 46.53 & 324.1 & 2.25 & 62.69 \\
1973 & 6935.4 & 31.20 & 20.92 & 1104.6 & 17.59 & 54.72 & 392.7 & 21.16 & 75.96 \\
1974 & 10064.2 & 45.11 & 30.36 & 1253.8 & 13.51 & 62.11 & 457.6 & 16.54 & 88.53 \\
1975 & 11577.8 & 15.04 & 34.93 & 1589.8 & 26.80 & 78.75 & 596.2 & 30.27 & 115.33 \\
1976 & 11960.7 & 3.31 & 36.08 & 1847.1 & 16.18 & 91.49 & 544.2 & -8.72 & 105.28 \\
1977 & 10774.7 & -9.92 & 32.51 & 1361.3 & -26.30 & 67.43 & 442.4 & -18.71 & 85.58 \\
1978 & 14346.3 & 33.15 & 43.28 & 1632.7 & 19.94 & 80.87 & 612.3 & 38.39 & 118.44 \\
1979 & 21134.1 & 47.31 & 63.76 & 2246.6 & 37.60 & 111.28 & 820.0 & 33.93 & 158.63 \\
1980 & 33146.6 & 56.84 & 100.00 & 2018.8 & -10.14 & 100.00 & 757.0 & -7.68 & 146.45 \\
1981 & 44066.1 & 32.94 & 132.94 & 2492.4 & 23.46 & 123.46 & 950.1 & 25.50 & 183.79 \\
1982 & 34224.9 & -22.33 & 103.25 & 1421.1 & -42.98 & 70.39 & 424.2 & -55.35 & 82.06 \\
1983 & 23526.3 & -31.26 & 70.98 & 1142.5 & -19.60 & 56.59 & 334.8 & -21.09 & 64.76 \\
1984 & 28664.9 & 21.84 & 86.48 & 1520.5 & 33.09 & 75.32 & 475.9 & 42.17 & 92.06 \\
1985 & 29537.7 & 3.04 & 89.11 & 1594.4 & 4.86 & 78.98 & 546.9 & 14.91 & 105.79 \\
1986 & 25842.9 & -12.51 & 77.97 & 1557.9 & -2.29 & 77.17 & 487.6 & -10.84 & 94.33 \\
1987 & 26602.1 & 2.94 & 80.26 & 1577.3 & 1.25 & 78.13 & 541.0 & 10.95 & 104.66 \\
1988 & 35032.5 & 31.69 & 105.69 & 2092.0 & 32.63 & 103.63 & 732.2 & 35.34 & 141.64 \\
1989 & 42034.1 & 19.99 & 126.81 & 2702.4 & 29.18 & 133.86 & 994.0 & 35.75 & 192.28 \\
1990 & 43633.4 & 3.80 & 131.64 & 3259.6 & 20.62 & 161.46 & 1190.2 & 19.74 & 230.23
\end{tabular}

FUENTE: 10 años de indicadores económicos y sociales de México. 1987; Agenda estadística, 1989; Indicadores económicos, varios números. Banco de México; La economía mexicana en cifras, 1988. Nacional Financiera, S.A.; Informes de gobierno, anexos estadisticos, varios años. Gobiemo del estado de Baja California.

1990: estimaciones.

Eg. tot.: Egresos totales del sector externo mexicano.

Eg. If.: Ingresos del sector externo por concepto de transacciones fronterizas, para la zona y perímetros libres, y para Baja California. TCMA: Tasa de crecimiento media anual.

fndice 1980: fndice de comportamiento base $1980=100$. 


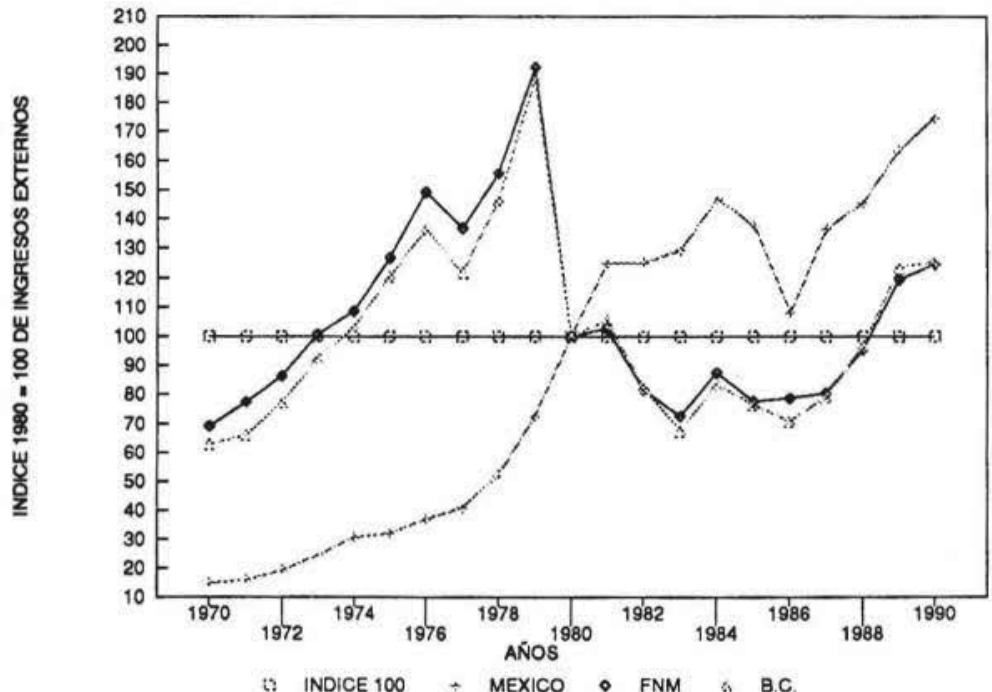

FIGURA 6. Índice 1980 ingresos externos 1970-1990 (México, FNM y B.C.).

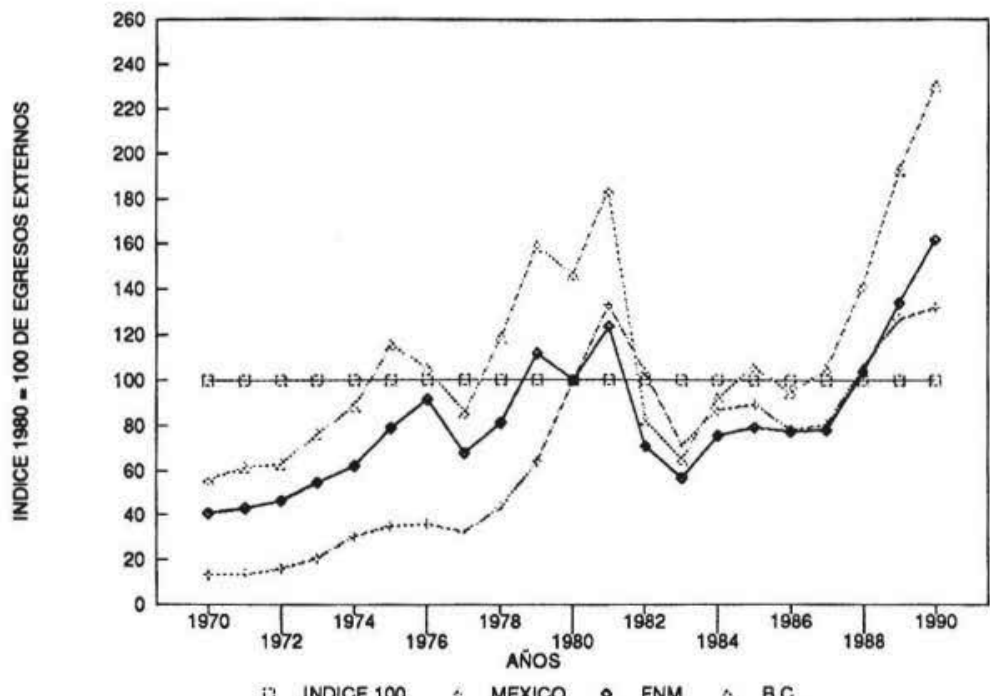

FIGURA 7. Índice 1980 egresos externos 1970-1990 (México, FNM y B.C.). 
más regular que los egresos: baste señalar que los ingresos tienden a una baja, mientras que los egresos fluctúan más. Entonces tenemos que: 1) Es en las importaciones donde los ajustes económicos y monetarios se resienten de manera palpable: en la primera fase -1970-1976 - existe un comportamiento sin cambios bruscos de su valor; en cambio en la fase de 1977-1981 hay un crecimiento veloz de las impontaciones que termina en 1982; desde entonces las importaciones en la entidad se encuentran a niveles de los primeros años de la década de los setenta. 2) La balanza comercial de la entidad es permanentemente deficitaria en todo el período; sus máximos valores se encuentran en la fase de auge, cuando precisamente se ubica un mayor crecimiento económico.

En cuanto a los porcentajes de participación del sector comercial externo y de las transacciones fronterizas de la entidad en el sector comercial externo nacional destacan los siguientes hechos: la disminución constante de las exportaciones de la entidad en las nacionales: de $10 \%$ en 1970 a sólo $0.63 \%$ en 1988; la disminución de las importaciones, con excepción de la primera fase, $5 \%$ en $1970,6 \%$ en 1981 y de $2.50 \%$ para 1990 . La misma situación se presenta para los ingresos y egresos fronterizos.

Esta baja importante de la participación porcentual de la entidad en el sector comercial extemo del país puede explicarse por dos razones fundamentales: primera, existe una disminución real de los intercambios de la entidad desde 1976 debido a los desajustes en la paridad peso-dólar y, segunda, la participación de otras regiones del país en el sector externo han sido mayores que las de B.C., por ejemplo, de las zonas petroleras, pero también de nuevos polos de desarrollo como son Monterrey y algunos estados del centro del país.

Por lo tanto, se puede asegurar que el sector externo de la entidad es más sensible a los cambios del comportamiento de la economía nacional que el resto del país; esto se debe a que la "sensibilidad" económica de la entidad se encuentra sumamente relacionada con factores específicos de la frontera norte y por las profundas relaciones internacionales, en especial con la de Estados Unidos. En términos de valores, el sector externo de la entidad ha sufrido una caída considerable, no sólo en su relación a su participación en el país, sino también en relación a la economía interna de la entidad. Situación que parece no cambiar para los próximos años.

De cualquier manera, lo importante al respecto es destacar que efectivamente el sector externo en la entidad ha sufrido, primero, mayores cambios que los sucedidos a nivel nacional y que, segundo, el sector externo es más determinante para el comportamiento económico de la entidad que para el promedio del país. 
CUADRO 8. Balanzas del sector externo, total, transacciones fronterizas y comercial. México, frontera norte y Baja California (en millones de dólares corrientes) 1970-1990.

\begin{tabular}{|c|c|c|c|c|c|}
\hline Años & $\begin{array}{c}\text { Balanza } \\
\text { total }\end{array}$ & $\begin{array}{l}\text { Balanza en } \\
\text { Tf. de fn. }\end{array}$ & $\begin{array}{l}\text { Balanza en } \\
\text { Tf. de B.C. }\end{array}$ & $\begin{array}{l}\text { Balanza comer- } \\
\text { cial México }\end{array}$ & $\begin{array}{l}\text { Balanza co- } \\
\text { mercial B.C. }\end{array}$ \\
\hline 1970 & $\left(\begin{array}{ll}1 & 188\end{array}\right)$ & 222 & 36 & $\left(\begin{array}{ll}1 & 211\end{array}\right)$ & (164) \\
\hline 1971 & $(929)$ & 308 & 24 & $(1058)$ & (160) \\
\hline 1972 & $(1006)$ & 374 & 74 & (1 297) & (184) \\
\hline 1973 & (1 529) & 422 & 85 & (2 094) & (138) \\
\hline 1974 & (3 226) & 397 & 75 & (3 692) & (234) \\
\hline 1975 & $(4442)$ & 336 & 26 & $(4066)$ & (222) \\
\hline 1976 & (3 683) & 420 & 158 & $(3024)$ & (207) \\
\hline 1977 & (1 597) & 716 & 187 & (1 373) & (142) \\
\hline 1978 & (2 692) & 731 & 144 & (2 273) & (259) \\
\hline 1979 & $(4869)$ & 673 & 152 & (3 157) & (394) \\
\hline 1980 & $(10740)$ & (498) & (240) & (3 698) & (493) \\
\hline 1981 & $(16052)$ & (933) & $(404)$ & $(4510)$ & (887) \\
\hline 1982 & $(6222)$ & (183) & 2 & 6793 & (770) \\
\hline 1983 & 5418 & (38) & 13 & 13307 & (106) \\
\hline 1984 & 4237 & (191) & (44) & 2265 & (340) \\
\hline 1985 & 1237 & (414) & (151) & 7852 & (397) \\
\hline 1986 & (1 673) & $(360)$ & (122) & 3820 & (136) \\
\hline 1987 & 3967 & (354) & (133) & 7896 & (23) \\
\hline 1988 & $(2443)$ & $(642)$ & (232) & 932 & (136) \\
\hline 1989 & $(5449)$ & $(890)$ & (357) & $(645)$ & (148) \\
\hline 1990 & $(4513)$ & $(1369)$ & (541) & 1656 & (173) \\
\hline
\end{tabular}




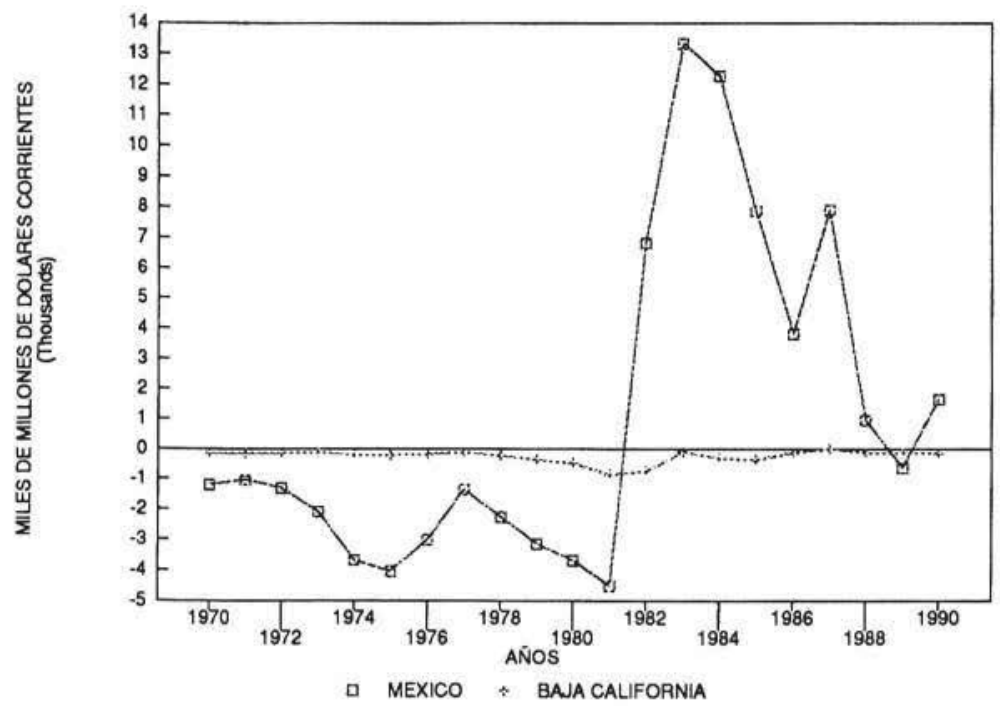

FIGURA 8. Balanza comercial 1970-1990 (México y Baja California).

\section{FRONTERA Y POLÍTICA ECONÓMICA}

Vamos a entender por frontera norte de México a los municipios de Baja California y a los municipios colindantes con los Estados Unidos. Desde principios de siglo esta región ha tenido un especial interés para el gobierno federal, ya que su cercanía con los Estados Unidos la hacen propicia a una especial atención por parte del centro del país.

En efecto, la prolongada existencia de la zona y perímetros libres y la "continua y extensiva aplicación de políticas especiales para la frontera, implementadas por el gobierno mexicano desde los años setenta a través de diferentes programas fronterizos, ha diferenciado el desarrollo fronterizo del resto del país" (Castillo, 1986:9). La acción del estado en la frontera norte de México (FNM) se divide en dos grandes campos: primero, en base al Programa Nacional Fronterizo (PRONAF) se plantearon objetivos de bienestar social: salud, vivienda, desarrollo urbano, educación y otros en la década de los sesenta. Segundo, desde principios de los setenta los objetivos sobre política económica se encaminaron más bien a impulsar acciones económicas para desarrollar la industria, el comercio y las exportaciones (Teutli, 1986:130). En la década de los ochenta la política 
económica para la FNM deja de ser tan clara como en las dos décadas anteriores, aunque sigue algunos patrones generales de los setenta pero sin introducir ninguna novedad.

La implementación de la política económica fronteriza, cubre dos grandes campos: a) consolidar la infraestructura mínima para los asentamientos humanos de la región, propiciando mecanismos de abasto en mercancías y bienes; $y, b$ ) estructurar un aparato económico "específico" para la frontera que permitiera el crecimiento sólido de la economía local, principalmente los referidos a comercio, turismo y maquiladoras.

Los programas, subprogramas y planes federales que más han influido en la dinámica de la FNM son nueve:

-Zonas y perímetros libres: 1933 al año en curso.

- Juntas federales de mejoras materiales: 1947-1961.

- Programa de braceros: 1942-1964.

- Programa nacional fronterizo (PRONAF): 1961-1965.

- Programa de industrialización fronteriza (PIF): 1965-1970.

- Programa de aprovechamiento de la mano de obra sobrante a lo largo de la frontera con los Estados Unidos o, también, Programa de la industria maquiladora para la FNM: 1965-1970.

- Programa de desarrollo económico fronterizo: 1971-1976:

- Creación de la comisión intersecretarial y de los comités de promoción económica (COPRODES):

- Programa de artículos gancho.

- Programa de comercialización fronteriza.

- Programa de centros comerciales.

- Programa de la industria maquiladora.

- Fomento a la industria fronteriza y decreto presidencial que declara de utilidad nacional a las pequeñas y medianas industrias establecidas en la franja fronteriza norte y en las zonas y perímetros libres; 1974.

- Programa para al fomento educativo de la franja fronteriza norte y zonas y perímetros libres: 1971 .

- Programa nacional de desarrollo de las franjas fronterizas y zonas libres: 1977-1982.

—Programa de desarrollo de la frontera norte (PDFN): 1985-1988.

Como se aprecia, fue en la década de los setenta cuando el gobiemo federal concentró su atención en el desarrollo de la FNM: los múltiples programas, planes y comisiones que se crearon en esos años en nada se parecen a la pobreza de planes y programas para la región en la década de los ochenta y al inicio de los noventa. 
La mayoria de los programas federales para la frontera se han dedicado a cumplir unos cuantos objetivos: combatir el desempleo, evitar la fuga de divisas, y propiciar la creación de infraestructura urbana e industrial (Ladman y Duffy, 1986:185). La primera decisión de política cconómica orientada específicamente a la FNM fue la creación del régimen de zona libre en 1933, la cual reconocía un hecho: la imposibilidad de abastecer a la región de bienes y servicios desde el centro del país (Zazueta, 1978:64).

Además, un objetivo paralelo a este último era el de permitir el acceso a materias primas desde los Estados Unidos que impulsara la creación de industrias locales para la demanda interna. ${ }^{23}$

Las juntas federales de mejoras materiales fueron también creadas específicamente para diseñar una política económica concreta para el crecimiento socioeconómico de la FNM (Zazueta, 1978:59), y se inauguraron como organismos auxiliares para el desarrollo regional. Sus acciones principales fueron el de ejecutar obras de infraestructura urbana y rural como abastecer de agua a los poblados, construcción de sistemas de drenaje y edificios públicos así como escuelas y otras. En "algunos casos llegaron incluso a subsidiar a los municipios" (Mendoza, 1982:50).

En el Programa Nacional Fronterizo (PRONAF) el gobiemo federal inicia una serie de programas de fomento económico en el que Nacional Financiera (NAFINSA) actuaría como institución fiduciaria. Los objetivos del PRONAF estaban dirigidos a que el crecimiento económico de la frontera implicara al mismo tiempo beneficios sociales a la población, es decir, fomento a la economía con bienestar social, intensificando, además, la integración de la FNM con el resto del país a partir de una creciente participación de mercancías nacionales en el consumo de la población fronteriza (Zazueta, 1978:155; Mendoza, 1982:52 y Sández, 1987:14), ${ }^{24}$ Estos últimos objetivos dejan de ser una prioridad en la década đe los ochenta y no aparecen en los noventa.

\footnotetext{
${ }^{23}$ Para algunos autores la zona libre en la FNM aparece como un mecanismo de integración a la economía norteamericana; es decir, "implica el reconocimiento de que la jurisdicción económica de nuestra burguesía - la mexicana - no alcanza cabalmente los ámbitos periféricos de la nación. Se abre asi la posibilidad de que la jurisdicción política entre en conflicto con la jurisdicciớn económica real" (Tamayo, 1988:133). A nuestro entender, este tipo de juicios pecan de exageración, en cuanto que la zona libre es un régimen juridico de relaciones comerciales internacionales y no un régimen especial de economia.

24 El PRONAF también implementó una serie de medidas operativas a nivel gubemamental como fue la formación de la Comisión intersecretarial para el fornento de la franja fronteriza norte y zonas y perímetros libres, cuyas tareas fueron de investigación, diagnósticos regionales, formulación de programss y orientación del desarrollo socioeconómico y urbano. Sus trabajos de investigación social fueron un parteaguas en las ciencias sociales en México y en especial, para la FNM. En 1977 dicha cornisión se reestructura con el nombre de Comisión Coordinadora del Programa Nacional de Desarrollo de las Franjas Fronterizas y Zonas Libres, cuyo objetivo principal se redujo en formular y determinar la forma en que las dependencias públicas federales debian de participar en el Programa Nacional Fronterizo.
} 
Bajo una concepción sustancialmente diferente al objetivo de integración nacional que proponía el PRONAF, en 1965 se inicia en la FNM el Programa de Industrialización Fronteriza (PIF) donde predominan los objetivos de corto plazo y que en resumidas cuentas queda enmarcado en el Programa de industrias maquiladoras.

Este último programa es el que más éxito tiene hasta hoy en día. ${ }^{25}$ El PIF se acompañó del Programa de Comercialización Fronteriza (PCF); los dos programas se constituyeron en documentos oficiales para la estrategia de política económica mexicana en la FNM. En términos generales en el PIF se definieron cuatro objetivos: 1) creación de empleos para reducir la tasa de desempleo; 2) elevación del ingreso y nivel de vida de la población fronteriza; 3) formación de mano de obra calificada; y, 4) incorporación de insumos nacionales en el producto de las plantas maquiladoras (Mendoza, 1982:55). Es en la creación de empleos donde el programa ha tenido mejores resultados; pero en cuanto a generación de tecnologías, consumo de insumos nacionales e irradiación sobre la industria de transformación sus resultados no son los señalados por los programas esperados. ${ }^{26}$

El PCF buscaba estimular la importación comercial, la concurrencia de mercancías nacionales y la creación de centros comerciales en las ciudades fronterizas. Este programa aceleró las importaciones, que en algunos casos desplazaba mercancías nacionales (Sández, 1987:15), pero al mismo tiempo logra introducir al mercado fronterizo algunas manufacturas mexicanas (Negrete, 1986:41). Sus resultados, fueron, pues contradictorios.

Por su parte, el Programa Nacional de Desarrollo de las Franjas Fronterizas y Zonas Libres de 1977-1982, y el Programa de Desarrollo de la Frontera Norte (PDFN) de 1985-1988 se establecieron ya no tanto como programas de desarrollo regional, como lo fueron el PRONAF y el PIF, sino como programas de ordenamientos para la administración pública federal en la FNM. En su contenido, los objetivos son repetitivos con los propuestos al inicio de la década de los setenta, con excepción del último donde el objetivo de integración nacional se establece de una manera secundaria.

\footnotetext{
25 Desde 1966 se establecieron las bases oficiales por parte de la Secretaría de Hacienda y de Industria y Cornercio para iniciar el crecimiento de la industria maquiladora dentro del PIP. El acuerdo fue llamado "Plan para aprovechamiento de la mano de obra sobrante a lo largo de la zona fronteriza"; éste permite la importación de maquinaria, equipo y materias primas a nuevas fábricas para producir artículos exclusivos a la exportación. Estas industrias se establecerian exclusivamente en los parques industriales que el PRONAP habís financiado (Zazueta, 1978; 189).

${ }^{26} \mathrm{La}$ contribución al ingreso de la población y al mejoramiento en los niveles de vida de dicha industria es cuestionable. Baste decir que sus éxitos más reconocidos se encuentran en la creación masiva de empleos para mujeres fronterizas.
} 
En Baja California se han implementado varios programas de desarrollo a nivel estatal y municipal: Plan Estatal de Desarrollo 1984-1989, cuyo contenido y forma reproduce los del Plan Nacional de Desarrollo 19831988. El Plan Municipal de Desarrollo 1987-1989 de Mexicali; este contiene también una estructura similar al estatal, pero con la virtud de poseer un análisis más amplio de los temas y un anexo estadístico bastante completo sobre el municipio de Mexicali y ser además, el primero en los municipios. Posteriormente, en 1990, se generaron planes de desarrollo en los dos niveles.

La política económica en la FNM se encuentra delineada en todos los programas y planes que hemos expuesto. Sin duda alguna, unos han tenido mejores resultados que otros: en especial han surtido efectos positivos aquéllos dirigidos al desarrollo industrial y comercial.

Desde la crisis de 1982, la mayoría de los objetivos propuestos en estos programas se encuentran cada vez más sujetos a las vicisitudes de la nueva política económica de apertura al mercado mundial, del libre comercio y de las transformaciones del estado benefactor a estado normativo, pero también a los cambios sustanciales del tipo de cambio, reestructuración industrial y comercio externo. Éstas son las principales razones de por qué desde la década de los ochenta los objetivos de política económica expresados en los programas de la FNM se reducen al ámbito de la propia administración de gobierno, y no al desarrollo integral de la región.

La evaluación cuantitativa de la política económica es bastante complicada, por eso sólo seleccionamos dos variables. el gasto público y la inversión federal donde tenemos datos anuales que son bastante representativos. El primero se presenta en el cuadro 9 y el segundo en el cuadro 10 , con sus respectivas figuras cuyas líneas están conformadas por el índice de comportamiento base $1980=100$.

Se aprecia en el cuadro 9 - gasto público - una situación: el comportamiento del gasto en la entidad tiende a ser menor que el promedio nacional; pero, además, después de 1982 no se recupera. Los resultados son bastante elocuentes: a precios constantes de 1978 para 1990 el gasto público nacional es 5\% mayor al de 1980; en los mismos términos, el de la entidad es casi un $25 \%$ menos.

El efecto de la crisis y la recesión ha implicado para la entidad mayores pérdidas en cuanto al comportamiento del gasto público, lo que conlleva no sólo paralización en obras y servicios, sino un deterioro físico y material de las obras públicas que durante años no se les atendió en su conservación y mantenimiento, repercutiendo directamente en el bienestar de la población.

En el mismo cuadro se advierte que la participación porcentual del gasto público estatal tiene una tendencia a disminuir en el nacional: en 
1970 el gasto de la entidad era el $0.38 \%$ del nacional; para 1980 del $0.35 \%$; en 1985 apenas es ya del 19\%; y sólo hasta 1990 llega a recuperarse relativamente al $0.25 \%$. Esto a pesar de que B.C. participa en la población total de México en 2.16\% en 1990.

CUADRO 9. Gasto público presupuestal de México y Baja California (a precios constantes de 1978 y en millones de pesos) 1970-1990.

\begin{tabular}{|c|c|c|c|c|c|c|c|}
\hline \multirow[b]{2}{*}{ Años } & \multicolumn{2}{|c|}{ México; } & \multirow{2}{*}{$\begin{array}{l}\text { Indice } \\
\text { a } 1980\end{array}$} & \multicolumn{2}{|c|}{ Baja Califormia: } & \multirow{2}{*}{$\begin{array}{l}\text { fndice } \\
\text { a } 1980\end{array}$} & \multirow{2}{*}{$\begin{array}{l}\% \text { de B.C } \\
\text { en Méxic }\end{array}$} \\
\hline & G.P. & TCMA & & G. P. & TCMA & & \\
\hline 1970 & 223619 & & 22.8 & 859 & & 25.1 & 0.38 \\
\hline 1971 & 234282 & 4.8 & 23.9 & 860 & 0.1 & 25.2 & 0.37 \\
\hline 1972 & 317594 & 35.6 & 32.4 & 879 & 2.1 & 25.7 & 0.28 \\
\hline 1973 & 409175 & 28.8 & 41,7 & 1202 & 36.8 & 35.2 & 0.29 \\
\hline 1974 & 439962 & 7.5 & 44.9 & 1294 & 7.7 & 37.9 & 0.29 \\
\hline 1975 & 599979 & 36.4 & 61,2 & 1626 & 25.7 & 47.6 & 0.27 \\
\hline 1976 & 651218 & 8.5 & 66.4 & 1932 & 18.8 & 56.5 & 0.30 \\
\hline 1977 & 776927 & 19.3 & 79.3 & 1876 & -2.9 & 54.9 & 0.24 \\
\hline 1978 & 846058 & 8.9 & 86.3 & 2759 & $4 \%, 1$ & 80.7 & 0.33 \\
\hline 1979 & 874668 & 3.4 & 89.2 & 2628 & -4.7 & 76.9 & 0.30 \\
\hline 1980 & 980145 & 12.1 & 100.0 & 3418 & 30.0 & 100.0 & 0,35 \\
\hline 1981 & 1220682 & 24.5 & 124.5 & 4671 & 36.6 & 136.6 & 0.38 \\
\hline 1982 & 1093732 & $-10,4$ & 111.6 & 3575 & -23.4 & 104,6 & 0.33 \\
\hline 1983 & 1128206 & 3.2 & 115.1 & 2333 & -34.7 & 68.3 & 0.21 \\
\hline 1984 & 1185611 & 5.1 & 121.0 & 1985 & -14.9 & 58.1 & 0.17 \\
\hline 1985 & 1149589 & -3.0 & 117.3 & 2217 & 11.7 & 64.8 & 0.19 \\
\hline 1986 & 1197296 & 4.1 & 122.2 & 1653 & -25.4 & 48.4 & 0.14 \\
\hline 1987 & 1252102 & 4.6 & 127.7 & 1164 & -29.6 & 34.0 & 0.09 \\
\hline 1988 & 1047225 & -16.4 & 106.8 & 1502 & 29.1 & 43.9 & 0.14 \\
\hline 1989 & 1000483 & -4.5 & 102.1 & 1682 & 12.0 & 49.2 & 0.17 \\
\hline 1990 & 1028091 & 2.8 & 104.9 & 2578 & 53.3 & 75,4 & 0.25 \\
\hline
\end{tabular}

FUENTE: Indicadores económicos, Banco de México; Anuario estadistico de los Estados Unidos Mexicanos, 1987, INEGl; Informes de gobierno. Gobiemo del estado de Baja California; La economía mexicana en cifras, 1988. NAFINSA; Agenda estadistica del municipio de Mexicali, Baja California, 1990, XIII Ayuntamiento de Mexicali; Cuadernos de estudios y proyectos, 1990. Cuadernos de informacion oportuna. INEGI.

G.P. Gasto público 
CUADRO 10. Inversión pública federal presupuestada de México y Baja California (a precios constantes de 1978 y en millones de pesos) 1970-1990.

\begin{tabular}{|c|c|c|c|c|c|c|c|}
\hline \multirow[b]{2}{*}{ Años } & \multicolumn{2}{|c|}{ México: } & \multirow{2}{*}{$\begin{array}{l}\text { fndice } \\
\text { a } 1980\end{array}$} & \multicolumn{2}{|c|}{ Baja California } & \multirow{2}{*}{$\begin{array}{l}\text { fndice } \\
\text { a } 1980\end{array}$} & \multirow{2}{*}{$\begin{array}{l}\text { \% de B.C } \\
\text { en Méxic }\end{array}$} \\
\hline & I. P. & TCMA & & I. P. & TCMA & & \\
\hline 1970 & 90418 & & 27.8 & 2409 & & 28.0 & 2.66 \\
\hline 1971 & 65871 & -27.1 & 20.2 & 1767 & -26.7 & 20.5 & 2.68 \\
\hline 1972 & 93271 & 41.6 & 28.6 & 2807 & 58.9 & 32.6 & 3.01 \\
\hline 1973 & 124596 & 33.6 & 38.3 & 3446 & 22.8 & 40.1 & 2.77 \\
\hline 1974 & 130943 & 5.1 & 40.2 & 2894 & -16.0 & 33,6 & 2.21 \\
\hline 1975 & 168012 & 28.3 & 51.6 & 4035 & 39.4 & 46.9 & 2.40 \\
\hline 1976 & 164562 & -2.1 & 50.5 & 3862 & -4.3 & 44.9 & 2.35 \\
\hline 1977 & 159932 & -2.8 & 49.1 & 3639 & -5.8 & 42.3 & 2.28 \\
\hline 1978 & 215821 & 34.9 & 66.3 & 4991 & 37.2 & 58.0 & 2.31 \\
\hline 1979 & 265440 & 23.0 & 81.5 & 4759 & -4.7 & 55.3 & 1.79 \\
\hline 1980 & 325638 & 22.7 & 100.0 & 8602 & 80.8 & 100.0 & 2.64 \\
\hline 1981 & 396910 & 21.9 & 121.9 & 8427 & -2.0 & 98.0 & 2.12 \\
\hline 1982 & 336323 & -15.3 & 103.3 & 6271 & -25.6 & 72.9 & 1.86 \\
\hline 1983 & 222782 & -33.8 & 68.4 & 2800 & -55.4 & 32.5 & 1.26 \\
\hline 1984 & 223192 & 0.2 & 68.5 & 3560 & 27.1 & 41.4 & 1.59 \\
\hline 1985 & 189389 & -15.1 & 58.2 & 3010 & -15.4 & 35.0 & 1.59 \\
\hline 1986 & 163447 & -13.7 & 50.2 & 2617 & -13.0 & 30.4 & 1.60 \\
\hline 1987 & 156330 & -4.4 & 48.0 & 2546 & -2.7 & 29.6 & 1.63 \\
\hline 1988 & 76206 & -51.3 & 23.4 & 1254 & -50.8 & 14.6 & 1.65 \\
\hline 1989 & 90697 & 19,0 & 27.9 & 1389 & 10.8 & 16.1 & 1.53 \\
\hline 1990 & 108652 & 19.8 & 33.4 & 1182 & -14.9 & 13.7 & 1.09 \\
\hline
\end{tabular}

FUENTE: Las mismas del cuadro 9; "Informes de gobierno, anexos estadísticos." Gobiemo federal.

I.P. Inversión Pública.

Comportamiento parecido sucede con la inversión pública: en términos de TCMA México sufre durante todo el período 8 años con tasas negativas; en cambio, B.C. tiene 13, muchos de los cuales llegan a ser del $-50 \%$ de un año a otro.

Si tomamos del índice de comportamiento $1980=100$, la situación aparece catastrófica para la entidad. En 1990 apenas representaba a valores constantes de 1978, un 14\% (aproximadamente), de la ejercida en 1980 , mientras que a nivel nacional es del $34 \%$ en los mismos términos. 


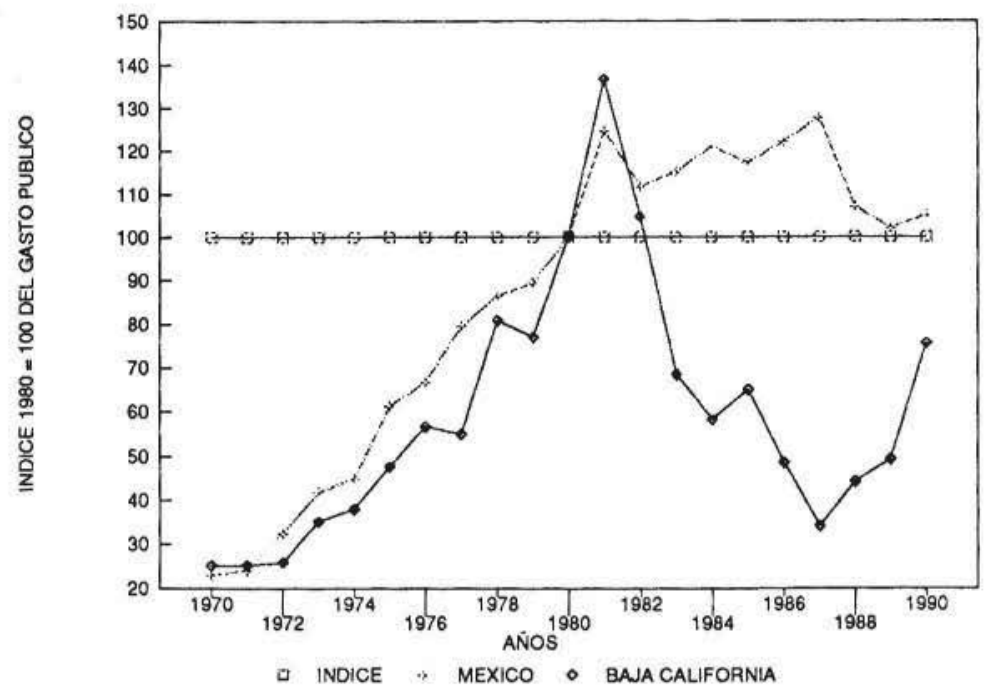

FIGURA 9. Índice 1980 de gasto público 1970-1990; México y Baja California.

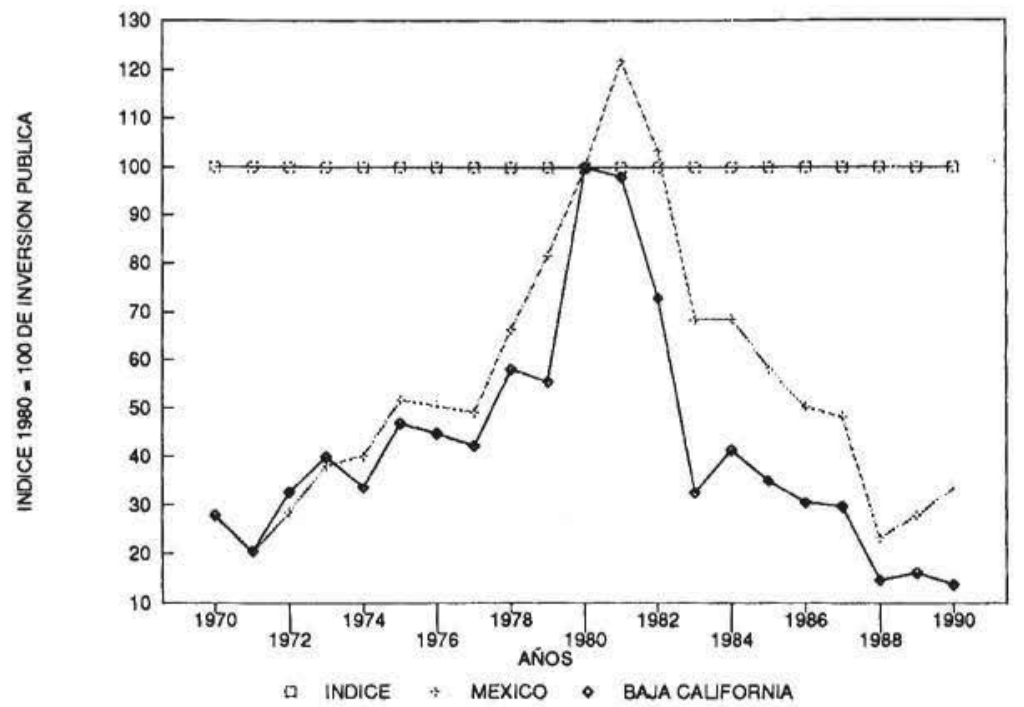

FIGURA 10. Índice 1980 inversión pública 1970-1990; México y Baja California. 
Sin duda alguna, a pesar de que en la fase de auge - 1977-1981- el gasto y la inversión pública tuvieron aumentos anuales hasta del $25 \%$ y del $37 \%$ a nivel nacional y estatal, respectivamente, la configuración posterior de estas dos variables han sido comportamientos con tendencia cada vez más hacia la baja, situación que se explica por las propias crisis de las cuentas públicas, el descontrol y abuso de los presupuestos por parte de las autoridades respectivas y, fundamentalmente, por la falta de un eficiente diagnóstico de la realidad socioeconómica y técnica de las regiones que permitiera eficientizar los recursos públicos y con esto crear efectos multiplicadores adecuados en las economías.

\section{CONCLUSIONES}

Baja California es una entidad fronteriza en donde se resienten, de forma ampliada, los problemas de la economía nacional, fundamentalmente aquéllos que están en el área del sector externo: comercio exterior y devaluaciones. La pérdida de las "ventajas fronterizas" son notables: una caída, principalmente durante la crisis, de las importaciones para insumos comerciales, industriales y de la población, desajustes monetarios por los cambios de la paridad peso-dólar que desajustan de manera drástica los ingresos y egresos de las empresas y de las familias fronterizas.

La pérdida de los tradicionales niveles de vida de la población bajacaliforniana todavia no ha sido cuantificada de manera objetiva y científica; pero es evidente que B.C. ha transformado sus pautas económicas fundamentalmente desde la crisis de 1982. Su futuro ahora está precisamente en una disyuntiva: la interdependencia histórica de la entidad no sólo debe ya de generar crecimiento económico, como parece ser que viene dándose desde 1989, sino derramar sus efectos en el bienestar social de la población bajacalifomiana.

El contexto nacional no puede ser subestimado: Baja California forma parte de la avanzada de cambios que actualmente está impulsando la política económica del actual régimen federal. Para la economía de la entidad no son extrañas las relaciones libres de comercio, ni la configuración competitiva de mercados internacionales tanto en la industria, en el comercio y en los servicios. Esta situación se presenta como un indicador positivo para la incrustación de la entidad en el Tratado de Libre Comercio con Estados Unidos y Canadá.

Una manera de concluir este trabajo, no muy común, sería presentar los resultados de nuestras variables interactuando entre sí. Para esto hemos construido los tres últimos cuadros: cuadro 11: relaciones entre el producto interno bruto (PIB) con la inversión y el gasto público (IPF y GP). Cuadro 12: per cápita de las variables PIB, gasto e inversión pública. Y, cuadro 13: 
per cápita de las variables que conforman, en este caso, el sector externo. Todos ellos con sus respectivas figuras representativas.

La relación GP/PIB en México tiene una tendencia, durante todo el período, de un aumento paulatino, aunque el índice base 1980 sufre una caída posterior a 1982, éste no cae más allá del 100. Donde aparecen cambios bruscos es en la relación IPF/PIB: una constante de alrededor del $6 \%$ durante los primeros años de los setenta; un aumento considerable durante el auge petrolero; $y$, posteriormente, una caída aguda hasta llegar a representar aproximadamente el $4 \%$ del PIB nacional.

CUADRO 11, Relaciones entre el producto interno bruto (PIB) con el gasto publico (GP) y la inversion publica federal (IPF). Mexico y Baja California 1970-1990.

\begin{tabular}{|c|c|c|c|c|c|c|c|c|}
\hline Años & $\begin{array}{c}\text { México } \\
\text { GP/PI }\end{array}$ & $\begin{array}{l}\text { Indice } \\
\text { a } 1980\end{array}$ & IPF/PIB & $\begin{array}{l}\text { Indice } \\
\text { a } 1980\end{array}$ & $\begin{array}{l}\text { B.C. } \\
\text { GP/PI }\end{array}$ & $\begin{array}{l}\text { Indice } \\
\text { a } 1980\end{array}$ & IPF/PIB & $\begin{array}{l}\text { Indice } \\
\text { a } 1980\end{array}$ \\
\hline 1970 & 16.26 & 47.51 & 6.57 & 57.82 & 2.49 & 48.40 & 6.98 & 53.93 \\
\hline 1971 & 16.26 & 47.51 & 4.57 & 40.20 & 2.31 & 45.00 & 4.75 & 36.73 \\
\hline 1972 & 20.08 & 58.67 & 5.90 & 51.86 & 2.35 & & 7.50 & 57.99 \\
\hline 1973 & 23.69 & 69.23 & 7.21 & 63 & 2.98 & 1 & 8.53 & 65.95 \\
\hline 1974 & 24.21 & 70.74 & 7.20 & 63.37 & 2.96 & 3 & 6.61 & 1.11 \\
\hline 1975 & 31.09 & 90.85 & 8.71 & 76.58 & 3.55 & 69.08 & 8.81 & 68.10 \\
\hline 1976 & 31.35 & 91.62 & 7.92 & 69.68 & 4.08 & 79.41 & 8.16 & 63.05 \\
\hline 1977 & 35.75 & 104.48 & 7.36 & 64.74 & 3.80 & 7 & 7.37 & 56.94 \\
\hline 1978 & 36.20 & 105.78 & & & 0 & 97 & 9.04 & .87 \\
\hline 1979 & 33.70 & & 10.23 & & & & 7.98 & 61.68 \\
\hline 1980 & 34.22 & 100.00 & 11.37 & 100.00 & S.14 & 100.00 & 12.94 & 100.00 \\
\hline 1981 & 39.71 & 116.05 & 12.91 & 113.57 & 6.29 & 122.40 & 11.35 & 87.75 \\
\hline 1982 & 35.26 & 103.05 & 10.84 & 95.38 & 4.51 & 87.78 & 7.91 & 61.18 \\
\hline 198 & 38.68 & & & & & 60. & 3.72 & 28.75 \\
\hline 1984 & 40.80 & 119.22 & 7.68 & 67.55 & 2.71 & 52.63 & 4.85 & 37.51 \\
\hline 1985 & 38.80 & 113.40 & 6.39 & 56.23 & 3.15 & 61.23 & 4.27 & 33.04 \\
\hline 1986 & 44.90 & 131.22 & 6.13 & 53.92 & 2.32 & 45.18 & 3.68 & 28.42 \\
\hline 1987 & 44.70 & 130.63 & & & 1.63 & & 3.57 & 27.61 \\
\hline 198 & 39.13 & & & & 2.10 & & 1.75 & 13.53 \\
\hline 1989 & 36.15 & 105.63 & 3.28 & 28.82 & 2.31 & 44.85 & 1.90 & 14.71 \\
\hline 1990 & 36.06 & 105.38 & 3.81 & 33.52 & 3.40 & 66.15 & 1.56 & 12.05 \\
\hline
\end{tabular}

FUENTE: Cuadros 3,9 y 10. 
CONFIGURACIONN ECONOMICA DE BAJA CALIFORNIA

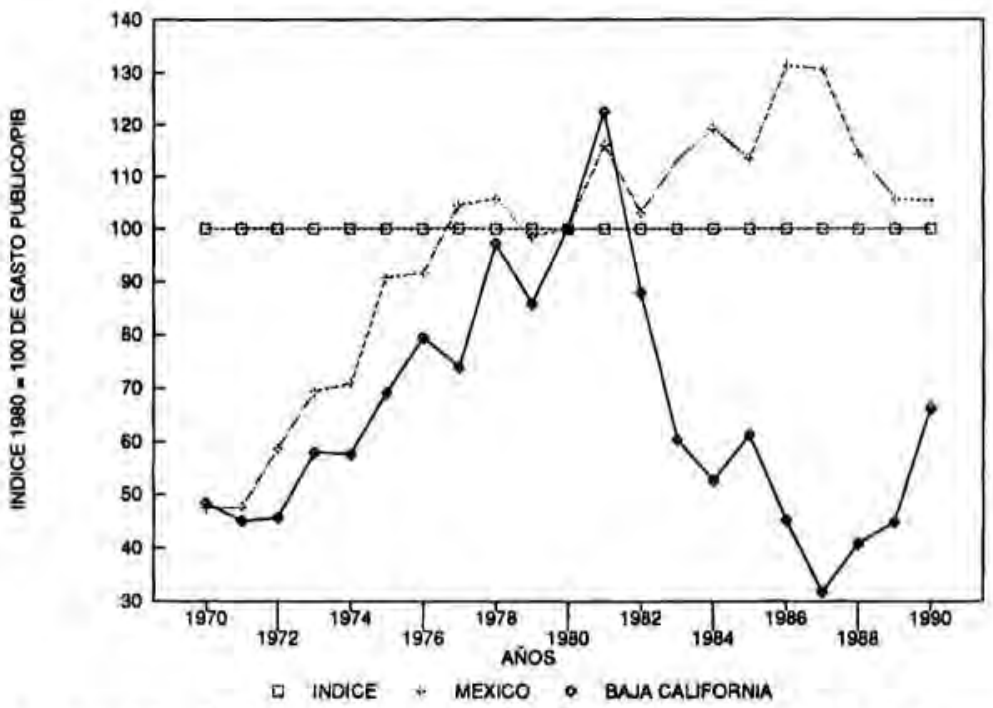

FIGURA 11a. Índice 1980 de GP/PIB 1970-1990, México y Baja California.

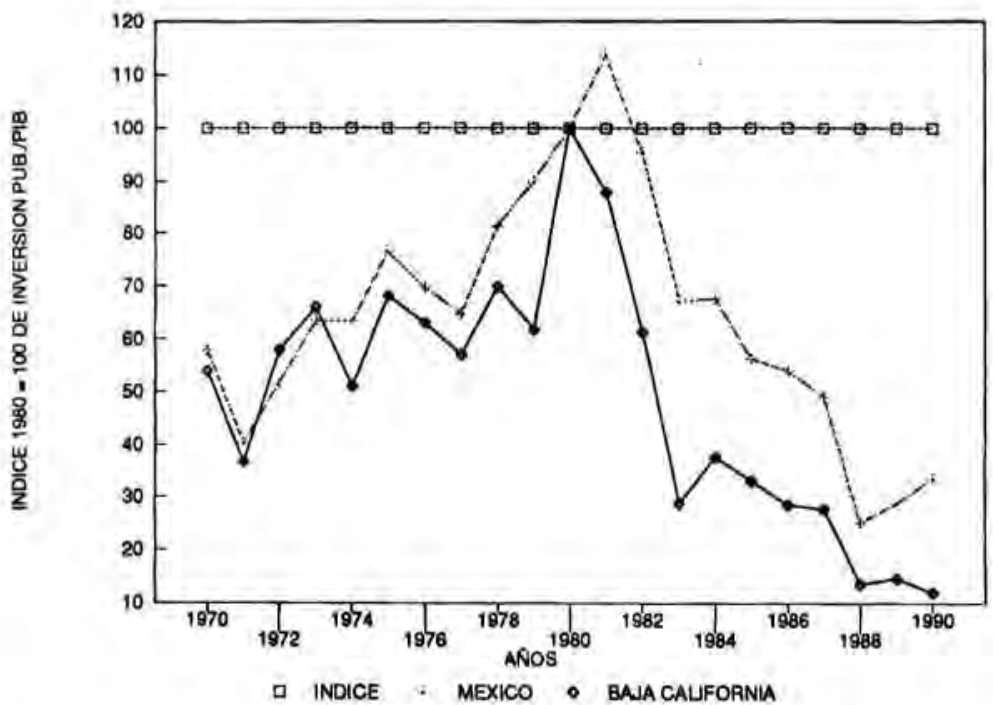

FIGURA 11b. Índice 1980 de IPF/PIB 1970-1990, México y Baja California. 
En los mismos términos la tendencia en la relación GP/PIB para Baja California, aunque no llega a las proporciones nacionales, responde al comportamiento nacional. En cambio, en la relación IPF/PIB de B.C. la tendencia hacia la baja es mucho más profunda que la nacional, como lo demuestra el índice de comportamiento.

En el cuadro 12 las dos primeras columnas expresan el ingreso per cápita nacional y estatal. Aquí vale la pena señalar que si bien en todo el período el ingreso estatal es mayor, en términos absolutos, que el nacional, 40 y 33 miles de pesos respectivamente en 1990, la tendencia a la disminución es más fuerte para Baja California; lo cual nos habla de una pérdida del poder adquisitivo relativamente mayor.

CUADRO 12. Per cápita del sector interno. México y Baja California (sector interno en miles de pesos a precios constantes de 1978).

\begin{tabular}{lcccccc}
\hline Año & $\begin{array}{c}\text { México } \\
\text { PIB }\end{array}$ & $\begin{array}{c}\text { B.C. } \\
\text { PIB }\end{array}$ & $\begin{array}{c}\text { México } \\
\text { G.P. }\end{array}$ & $\begin{array}{c}\text { B.C. } \\
\text { G.P. }\end{array}$ & $\begin{array}{c}\text { México } \\
\text { I.P. }\end{array}$ & $\begin{array}{c}\text { B.C. } \\
\text { I.P. }\end{array}$ \\
\hline & & & & & & \\
1970 & 28.52 & 39.67 & 4.64 & 0.99 & 1.87 & 2.77 \\
1971 & 28.71 & 40.68 & 4.67 & 0.94 & 1.31 & 1.93 \\
1972 & 30.27 & 38.99 & 6.08 & 0.92 & 1.78 & 2.92 \\
1973 & 31.75 & 40.08 & 7.52 & 1.19 & 2.29 & 3.42 \\
1974 & 32.10 & 41.36 & 7.77 & 1.22 & 2.31 & 2.73 \\
1975 & 32.74 & 41.22 & 10.18 & 1.46 & 2.85 & 3.63 \\
1976 & 34.09 & 41.21 & 10.69 & 1.68 & 2.70 & 3.36 \\
1977 & 34.49 & 41.34 & 12.33 & 1.57 & 2.54 & 3.05 \\
1978 & 35.88 & 44.44 & 12.99 & 2.22 & 3.31 & 4.02 \\
1979 & 38.52 & 46.15 & 12.98 & 2.03 & 3.94 & 3.68 \\
1980 & 41.12 & 49.19 & 14.07 & 2.53 & 4.68 & 6.36 \\
1981 & 43.15 & 53.04 & 17.14 & 3.34 & 5.57 & 6.02 \\
1982 & 42.58 & 54.69 & 15.01 & 2.47 & 4.62 & 4.33 \\
1983 & 39.16 & 50.18 & 15.14 & 1.56 & 2.99 & 1.87 \\
1984 & 38.15 & 47.25 & 15.56 & 1.28 & 2.93 & 2.29 \\
1985 & 38.03 & 43.80 & 14.76 & 1.38 & 2.43 & 1.87 \\
1986 & 33.55 & 42.99 & 15.06 & 1.00 & 2.06 & 1.58 \\
1987 & 34.54 & 41.80 & 15.44 & 0.68 & 1.93 & 1.49 \\
1988 & 32.34 & 40.76 & 12.65 & 0.86 & 0.92 & 0.71 \\
1989 & 32.78 & 40.34 & 11.85 & 0.93 & 1.07 & 0.77 \\
1990 & 33.09 & 40.69 & 11.93 & 1.38 & 1.26 & 0.63 \\
& & & & & & \\
\hline
\end{tabular}

FUENTE: Cuadros $1,3,9$ y 10. 


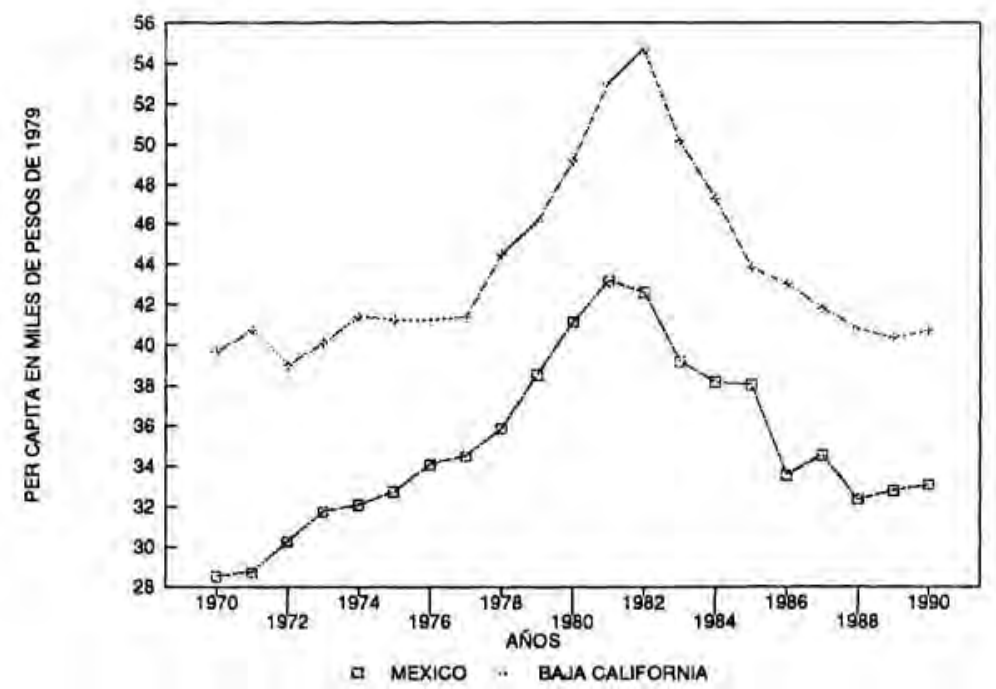

FIGURA 12a. Per cápita población/PIB 1970-1990. México y Baja California.

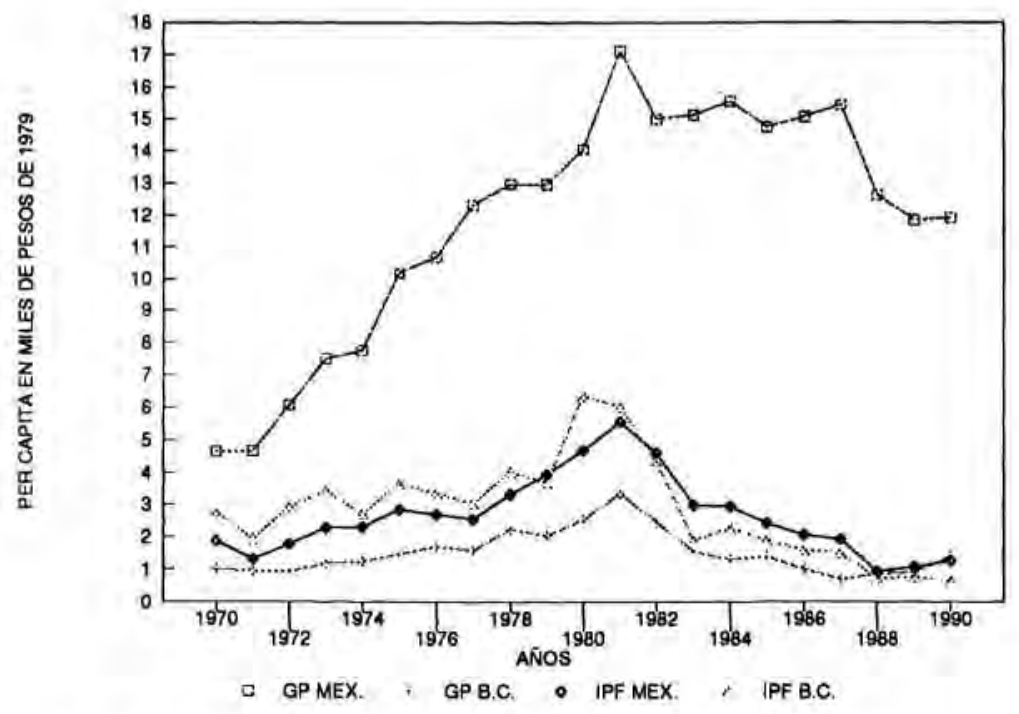

FIGURA 12b. Per cápita POB/PIB e IPF 1970-1990. México y Baja California. 
Otra situación definitoria se encuentra en los per cápita del GP y de la IPF: en el primero la desventaja de la entidad es evidente, más si se consideran los últimos años de los ochenta. En cuanto al segundo, la situación difiere: en la década de los setenta era mayor el de B.C., posteriormente esta ventaja se pierde y hasta es menor que el nacional. Para 1990, la IPF per cápita de la entidad es casi $100 \%$ menor que el nacional. De nuevo observamos que la política de gasto e inversión ha sido sumamente desfavorable para Baja California.

Y, para cerrar, en el cuadro 13 presentamos los per cápítas del sector externo donde incluimos al conjunto de las transacciones fronterizas. En cuanto a los ingresos per cápitas totales del país y de la frontera, parece existir coherencia en su dinámica; pero en los per cápitas de exportaciones

\section{Cuadro 13, Per cápita del sector externo. México y Baja California (sector externo en dólares corrientes).}

\begin{tabular}{lrrrrrrrrr}
\hline & México & B.C & México & B.C. & México & B.C. & México & B.C. \\
Año & In. tot. & In. tf. & X-Méx & X-B.C. & Eg. tot. & Eg. tf. & M-Méx. M-B.C. \\
\hline & & & & & & & & & \\
1970 & 67.48 & 373.99 & 26.74 & 137.93 & 92.11 & 333.02 & 51.85 & 326.41 \\
1971 & 70.37 & 373.20 & 27.20 & 131.87 & 88.87 & 346.79 & 48.28 & 307.02 \\
1972 & 81.91 & 414.63 & 31.89 & 160.23 & 101.16 & 337.69 & 56.72 & 352.28 \\
1973 & 99.39 & 474.08 & 38.09 & 328.80 & 127.50 & 389.66 & 76.58 & 465.78 \\
1974 & 120.77 & 503.73 & 50.39 & 131.56 & 177.74 & 432.46 & 115.59 & 353.04 \\
1975 & 121.07 & 559.66 & 51.96 & 145.74 & 196.43 & 536.54 & 120.95 & 345.68 \\
1976 & 135.83 & 611.63 & 59.98 & 176.21 & 196.26 & 473.68 & 109.61 & 356.17 \\
1977 & 145.65 & 526.64 & 73.79 & 160.94 & 170.99 & 370.27 & 95.58 & 279.94 \\
1978 & 178.87 & 608.81 & 93.06 & 190.95 & 220.19 & 492.70 & 127.95 & 399.46 \\
1979 & 241.44 & 752.20 & 130.89 & 300.08 & 313.72 & 634.49 & 177.75 & 604.59 \\
1980 & 321.67 & 382.38 & 217.27 & 128.76 & 475.87 & 559.98 & 270.36 & 493.35 \\
1981 & 393.28 & 389.90 & 272.62 & 120.44 & 618.63 & 678.84 & 335.94 & 754.18 \\
1982 & 384.43 & 294.23 & 291.45 & 91.37 & 469.83 & 292.77 & 198.19 & 622.84 \\
1983 & 388.55 & 231.88 & 299.52 & 83.32 & 315.82 & 223.17 & 120.89 & 153.88 \\
1984 & 431.90 & 278.25 & 315.75 & 86.55 & 376.28 & 306.48 & 154.74 & 305.63 \\
1985 & 395.03 & 246.01 & 280.68 & 128.95 & 379.15 & 340.18 & 179.89 & 375.99 \\
1986 & 304.07 & 220.66 & 198.46 & 152.98 & 325.11 & 294.50 & 150.41 & 235.12 \\
1987 & 376.90 & 239.19 & 254.68 & 178.50 & 328.00 & 317.24 & 157.34 & 191.80 \\
1988 & 393.81 & 284.77 & 249.63 & 181.04 & 423.33 & 416.86 & 238.36 & 258.47 \\
1989 & 433.28 & 351.83 & 269.61 & 192.36 & 497.81 & 549.43 & 277.24 & 274.17 \\
1990 & 454.07 & 348.52 & 308.79 & 183.01 & 506.46 & 638.73 & 289.56 & 276.04
\end{tabular}

FUENTE: Cuadros 1,6 y 7. 
nacionales y estatales se presenta un esfuerzo mayor a nivel nacional que en el estatal, más si se presenta los últimos años del período.

En cuanto a los egresos totales e importaciones, los efectos de la crisis y la recesión aparecen mucho más claros en contra de los per cápitas de Baja California, lo que viene a confirmar nuestra idea de que los impactos de los problemas económicos nacionales tienen un multiplicador mayor en la entidad vía sector externo.

A pesar de que la entidad históricamente tenía estos per cápitas considerablemente más altos que los nacionales, en los años finales de los ochenta igualan su dinámica a los valores nacionales, fundamentalmente en las importaciones per cápitas, llegando a ser unos 280 dólares per cápita de promedio para las dos unidades en 1990.

Es pues vía relaciones económicas internacionales que los problemas nacionales se manifiestan en la economía de la entidad, repercutiendo con mayor fuerza en el aparato productivo y comercial y en las economías familiares fronterizas con mayor profundidad que en el resto del país.

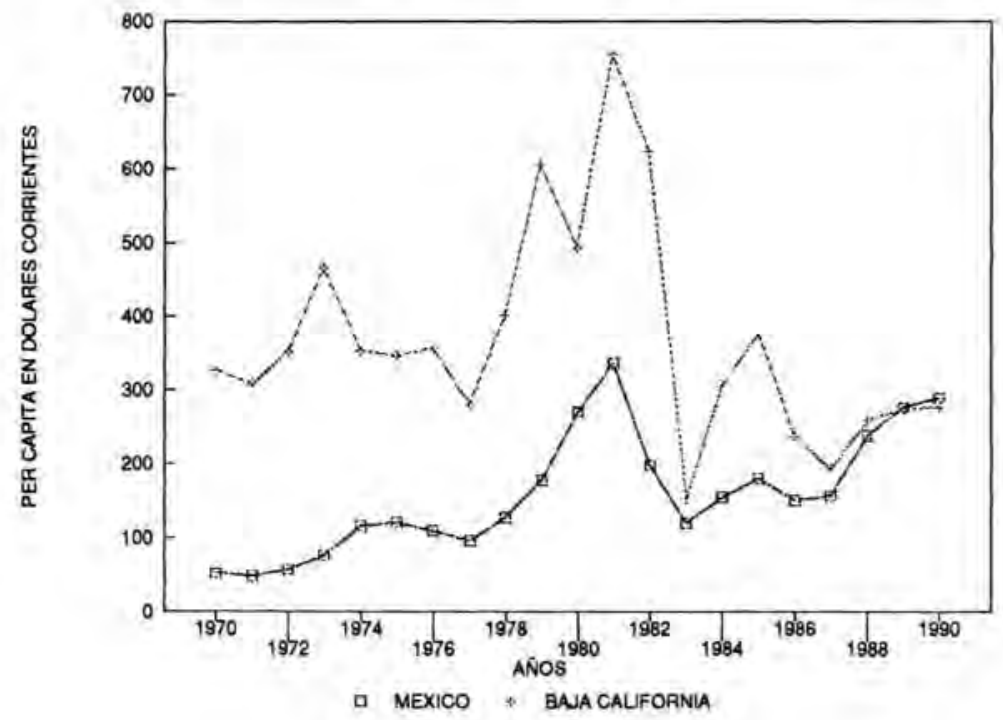

FIGURA 13, Per cápita en importaciones 1970-1990, México y Baja California. 
Frente a la nueva apertura comercial de México en el mundo del mercado, la entidad se encontrará con mayor sensibilidad a los ajustes y cambios que esta integración presupone; sus repercusiones positivas o negativas en la población bajacaliforniana serán resultados de respuestas que genere la sociedad económica, civil y política; $y$, fundamentalmente, según la capacidad que tengan los grupos económicos fronterizos para que los efectos positivos de la liberación comercial se redistribuyan de una forma más equitativa que la dada durante el período que presentamos.

\section{BIBLIOGRAFÍA}

BANCO DE MÉXICO. 1990. Indicadores económicos. Varios números. BOLTVINIK, Julio. 1986. "Modo de producción estatal y satísfacción de necesidades esenciales: el caso de México". Investigación económica, julio-septiembre de 1986. no. 177, Vol, XLV. Facultad de Economía, UNAM. México.

CABRERA Núñez, Gonzalo. 1987. "Diagnóstico del sector informal urbano en Baja California." Cuadernos de economia. Serie 3, no. 2. Facultad de Economía de la UABC. México.

CARRILlO Huerta, Mario Miguel. 1980. "Baja California: un panorama de su población y su economía". Editado por CNIET. México (mimeo).

- 1983. "La política cambiaria mexicana y la respuesta de la economía fronteriza del norte de México." Estudios fronterizos. Año I, no. 1, mayo-agosto de 1983. Is de la UABC. México.

CARRILLO Huerta, Mario; Ramón de Jesús Ramírez y Everardo V.1986. "Estructura y perspectiva de la actividad industrial en Baja California." Cuadernos de economia. No. 3, serie 2. Escuela de Economía de la UABC. México.

CASAR, José I, y Jaime Ros. 1984. "Comercio exterior y acumulación del capital en un proceso de sustitución de importaciones." Investigación económica. Vol. XLIII, no. 167, enero-marzo de 1984. Facultad de Economía de la UNAM. México.

CASTILLO, Víctor M, 1986. "Desarrollo regional y frontera norte. Configuración regional: 1960-1980.” Cuadernos de economia. Serie 2, no. 1. Escuela de Economía de la UABC, México.

CERVANTES, Jesús. 1982. "La inflación y la distribución del ingreso y la riqueza en México." Distribución del ingreso en México. Ensayos. Selección de Carlos Bazdresch y otros. Edita Banco de México. México. 
CONEPO-INEGI. Proyecciones de la población de México y de las entidades federativas (hipótesis de fecundidad alternativa).

CONTRERAS, Óscar. 1988. "La industria en Baja Califomia. 18901982." Historia y desarrollo industrial de México. Edita Confederación Nacional de Cámaras Industriales. México.

COPLADE DE BAJA CALIFORNIA. 1983. Estadisticas generales de Baja California.

CÓRDOBA, José y Guillermo Ortiz, 1980, “Aspectos deflacionarios de la devaluación del peso mexicano de 1976." Demografí y economía. Vol, XIV, no, 3 (43), El Colegio de México. México.

GARCÍA Montaño, Jorge. 1987. "Diagnóstico de largo plazo de la economía de Baja California. 1950-1980." Cuadernos de economía. Serie 3, no. 4. Escuela de Economía de la UABC. México.

GOBIERNO DE ESTADO DE BAJA CALIFORNIA. Varios años. Informe de gobierno, anexos estadísticos.

HERRERA Carrillo, Pablo. 1976. Colonización del valle de Mexicali. UABC.

INCO. 1984. "Cien días en el consumo familiar".

INEGI. 1987. 10 Años de indicadores económicos y sociales de México.

- 1987. Anuario estadístico de los Estados Unidos Mexicanos.

- 1989. Agenda estadística.

- $\quad$ s/f. Cuadernos de iformación oportuna.

- 1990. El ABC de las cuentas nacionales.

INEGI-SPP, 1991, XI Censo general de población y vivienda. Resultados preliminares.

- 1982. Sintesis geográfica del estado de Baja California.

LADMAN, Jerry R., y Michael K. Duffy. 1986. "Intercambio económico en el área fronteriza mexicana-norteamericana: comercio y turismo." Estudios fronterizos. Reunión de universidades de MéxicoEstados Unidos. Editorial ANUIES. México.

LLORÉNS Báez, Luis. 1983. "Baja California y la crisis económica de 1982 a través de la prensa." Cuadernos de ciencias sociales. Serie 1, no. 8. IS-UABC. México.

LÓPEZ Díaz, Pedro. 1978. "Crisis de estructura y capitalismo en México." Capitalismo y crisis en México. Pedro López Díaz y otros. Edit. ECP. México.

LÓPEZ G., Julio. 1987. "La economía mexicana: evolución reciente, perspectiva y alternativas." Investigación económica. Vol. XLII. no. 1983, abril-junio de 1987. Facultad de Economía de la UNAM. México.

MENDOZA Berrueto, Eliseo. 1981. "Algunos aspectos socioeconómicos de la frontera norte de la república mexicana." En: La frontera 
norte: integración y desarrollo. Roque González S. (compilador). El Colegio de México. México.

- 1982. "História de los programas federales para el desarrollo economico de la frontera norte." Administracion del desarrollo de la frontera norte. Mario Ojeda (compilador). El Colegio de México. Mexico.

NACIONAL FINANCIERA, S.A. 1988. La economia mexicana en cifras. NEGRETE Mata, José. 1986. "Integración e industrialización fronteriza. El caso de la ciudad industrial nueva de Tijuana." Tesis. El Colegio de la Frontera Norte. Tijuana, México.

OSWALD, Úrsula. 1987. "El impacto de la crisis en la estructura social de México." Aportes de investigación. No, 22. Centro Regional de Investigaciones Multidisciplinarias. UNAM. México.

PERZABAL, Carlos. 1987. "México: los años de inflación". Investigación económica, no. 181, julio-septiembre de 1987. Facultad de Economía, UNAM. México.

RAMÍREZ Acosta, Ramón de Jesús. 1983. "La conflictiva zona libre de Baja California." Economia informa. No. 110, noviembre de 1983. Facultad de Economía. UNAM. México.

RAMÍREZ Acosta, Ramón de J. y otros. 1985. "El impacto de la crisis cambiaria de 1982 en las relaciones económicas fronterizas: el caso Tijuana-San Diego." Cuadernos de economía. Serie I, no. 2. Escuela de Economía. UABC, México.

SÁNDEZ Pérez, Agustín. 1987. "Estructura y dinámica del sector manufacturero bajacaliforniano: 1960-1985." Cuadernos de ciencias sociales. Serie 3, no. 7. IIS de la UABC. México.

SIQUEIROS Canales, Joel. 1987. "El comercio entre California y Baja California: ¿relación fronteriza o vinculación binacional" Cuader. nos de economla. Serie 2, no. 5. Escuela de Economía. UABC. México.

SPP-INEGI-CELADE. "Estimaciones y proyecciones de población 1950. $2000^{\prime \prime}$.

TAMAYO, Jesús. 1982. "La frontera norte de México y la crisis de 1982: algunos comentarios preliminares." Estudiosfronterizos. AñoI, no. 1, mayo-agosto de 1982. IS-UABC. México.

- 1988. "Frontera, política regional y políticas nacionales en México." En: Una frontera-dos naciones. ANUIES/PROFMEX. México.

TEUTLI Otero, Guillermo, 1986, "La política federal de desarrollo fronterizo: análisis y perspectivas." Estudios fronterizos. Año IV, Vol. IV, Nos. 10-11, mayo-agosto y septiembre-diciembre de 1986. IIS-UABC. México. 
TRUJILLO Muñoz, Gabriel. 1988. Tres ensayos sobre el ensayo bajacaliforniano. Colección Cuadernos docentes, no. 5. UABC. México.

VALENZUELA Feijoó, José. 1986. El capitalismo mexicano en los ochentas. Era. Colección Problemas de México. México.

XIII AYUNTAMIENTO DE MEXICALI, 1990a. Agenda estadistica del municipio de Mexicali, Baja California, 1990, no. 3.

- 1990b. "Análisis de la validación de la población total de Mexicali, Baja California: 1990". Cuadernos de estudios y proyectos. No. 1 , septiembre.

ZAZUETA Quintero, Carlos. 1978. "La formación de la frontera norte; el caso de Baja California." Tesis del COLMEX. Maestría en ciencias políticas. México.

\section{Periódicos}

MURO, Ricardo del. 1986. "Descapitalizó la crisis a la frontera norte." En el periódico nacional UNOMASUNO. Del día 17 de julio al 6 de Agosto. México, 1986. 